\title{
Seismic Retrofit of Reinforced Concrete Frame Buildings with Hysteretic Bracing Systems: Design Procedure and Behaviour Factor
}

\author{
Antonio Di Cesare and Felice Carlo Ponzo \\ School of Engineering, University of Basilicata, Viale dell'Ateneo Lucano 10, 85100 Potenza, Italy \\ Correspondence should be addressed to Antonio Di Cesare; antodice@yahoo.it
}

Received 17 November 2016; Accepted 23 January 2017; Published 23 March 2017

Academic Editor: Ovidiu Vasile

Copyright (C) 2017 Antonio Di Cesare and Felice Carlo Ponzo. This is an open access article distributed under the Creative Commons Attribution License, which permits unrestricted use, distribution, and reproduction in any medium, provided the original work is properly cited.

\begin{abstract}
This paper presents a design procedure to evaluate the mechanical characteristics of hysteretic Energy Dissipation Bracing (EDB) systems for seismic retrofitting of existing reinforced concrete framed buildings. The proposed procedure, aiming at controlling the maximum interstorey drifts, imposes a maximum top displacement as function of the seismic demand and, if needed, regularizes the stiffness and strength of the building along its elevation. In order to explain the application of the proposed procedure and its capacity to involve most of the devices in the energy dissipation with similar level of ductility demand, a simple benchmark structure has been studied and nonlinear dynamic analyses have been performed. A further goal of this work is to propose a simplified approach for designing dissipating systems based on linear analysis with the application of a suitable behaviour factor, in order to achieve a widespread adoption of the passive control techniques. At this goal, the increasing of the structural performances due to the addition of an EDB system designed with the above-mentioned procedure has been estimated considering one thousand case studies designed with different combinations of the main design parameters. An analytical formulation of the behaviour factor for braced buildings has been proposed.
\end{abstract}

\section{Introduction}

The capacity of the structural systems to withstand seismic actions beyond the elastic range, by exploiting the intrinsic structural ductility, generally permits their design for seismic forces smaller than those corresponding to a linear elastic response. While attempting to minimise the effects of the seismic action, the use of a ductile behaviour often causes the development of excessive displacements that might lead to excessive structural and nonstructural damage [1].

In recent years, several innovative low-damage strategies for controlling the seismic response of buildings have been developed and put into practice. One of these considers the adoption of passive control approach, consisting in the use of Energy Dissipative Bracing (EDB) systems inserted into the structural frame. These systems are characterized by special devices able to dissipate large amounts of energy during a seismic event and significantly reduce the interstorey drifts of the braced structures [2-6]. The number of real applications of these techniques on new and existing buildings is rapidly increasing, mainly due to their effectiveness in reducing seismic effects, as demonstrated in the past studies carried out also by [7-11]. However, extensive studies are still required in order to provide more reliable analysis methods and practical design criteria, as the adoption of equivalent linear analysis [12-15].

Several seismic codes adopt simplified linear and nonlinear analysis methods for the design and seismic assessment of structures with supplemental dampers [16-20]. Elastic methods currently implemented in seismic codes take into account the nonlinear behaviour of conventional building structures using a behaviour factor $q$. The $q$ factor is an empirical quantity adopted to reduce the seismic force provided by the elastic response spectrum, allowing for performing linear elastic analysis for design of buildings. This approach focuses on determining the reduction factor starting from 
both the actual ductility capacity and the overstrength of the structure [21-23]. Typically, for reinforced concrete buildings, different values of $q$ factor are defined by codes as function of structural type and regularity criteria [24, 25]. Currently, for concrete framed buildings with EDB systems, the codes refer to approved methods, which typically account for the plasticization of both structure and EDBs, but specific behaviour factors for braced structures are not provided yet.

For these reasons the main goals of this study were (i) to define a simplified design procedure to sizing the EDBs based on Hysteretic Damper (HD) valid for the seismic retrofitting of existing reinforced concrete framed buildings; (ii) to define an estimation of behaviour factor due to the addition of hysteretic EDBs to existing frame.

To reach these goals, in Section 2 the paper provides an overview of the proposed design procedure based on nonlinear static analysis (NLSA), as defined by codes [24, 25]. Section 3 shows an application of the design procedure to a benchmark structure and the nonlinear dynamic analysis (NLDA) carried out in order to explain the simplicity of the procedure. Section 4 briefly summarizes the main outcomes of a parametric analysis carried out to evaluate the behaviour factor $q_{\mathrm{B}}$ of the braced building as function of the behaviour factor $q$ of the bare structure and of the main characteristics of the EDB system. Twenty concrete framed buildings, representing 1960s-1980s Italian reinforced concrete structures designed without specific seismic rules, have been investigated considering several combinations of design parameters of the EDBs. The results of about 1000 case studies have been examined through linear regression analysis in order to provide a formulation for the behaviour factor of braced structures.

\section{Design Procedure of Dissipative Bracing Systems}

The design procedure for retrofitting framed buildings with EDBs proposed in this paper is based on NLSA method, as described in the Italian and European seismic codes $[20,24]$. This method combines the pushover analysis of a multi-degree-of-freedom (MDOF) model with the response spectrum analysis of an equivalent singledegree-of-freedom (SDOF) system to provide an estimation of the global nonlinear displacement response exhibited by the structure under strong earthquakes $[16,20,24-$ 26]. The procedure imposes a maximum top displacement as function of the considered seismic input and regularizes the stiffness and strength along the height of the braced building by following the regularity criteria provided by seismic codes, achieving a quite uniform distribution of storey displacements and controlling the maximum interstorey drifts which must remain under the target limit.

The procedure, synthesized in Figure 1(a), evaluates the mechanical characteristics of the dissipative bracing system first for the equivalent SDOF system and then determines the characteristics of the braces along the building elevation. The distribution of dissipative braces inside the structural frames is function of the real geometry and position with the purpose to involve most of the devices in the energy dissipation with the same ductility demand. The optimal ranges for the design parameters are determined by referring to the results of experimental tests [27-32] and applications to real buildings $[33,34]$. As explained in the following, the symbols reported in Figure 1(b) refer to equivalent SDOF systems of elastoplastic structure (S); elastoplastic bracing system $(\mathrm{DB})$; elastic braced structure $(\mathrm{E}(\mathrm{S}+\mathrm{DB}))$; elastoplastic braced structure $(\mathrm{EP}(\mathrm{S}+\mathrm{DB}))$. A full list of symbols and abbreviations considered below is reported at the end of the paper.

Step 1 (evaluation of the equivalent SDOF system of the bare structure). The first step of the procedure is aimed at determining the mechanical characteristics of the equivalent SDOF system of the bare structure. The capacity curves can be determined through NLSA for both main directions of the building. At least two lateral load distributions should be applied (both uniform and modal pattern), in both the positive and negative direction, considering also 5\% accidental eccentricity of the centre of mass of each storey. The idealized elastoplastic force-displacement relationship of the structure $(S)$ is defined by the transformation factor $\Gamma$, the equivalent mass $m^{*}$, the yield force $F_{y}{ }^{*}$, the yield displacement $d_{\mathrm{y}}{ }^{*}$ (or the elastic stiffness $k_{F}{ }^{*}=F_{\mathrm{y}}{ }^{*} / d_{\mathrm{y}}{ }^{*}$ ), and the ultimate displacement $d_{\mathrm{u}}{ }^{*}$ (or the maximum ductility $\left.\mu_{F}{ }^{*}=d_{\mathrm{u}}{ }^{*} / d_{\mathrm{y}}{ }^{*}\right)$, as described in Annex-B of [24].

Step 2 (evaluation of the equivalent SDOF system of the dissipative bracing). The characteristics of the equivalent SDOF of the bracing system are determined by an iterative subroutine, applied separately for each main direction. The damped bracing (DB) system has been idealized as an elastoplastic system defined by the yield force $F_{\mathrm{DB}}$, the elastic stiffness $k_{\mathrm{DB}}$, and the design ductility $\mu_{\mathrm{DB}}$.

(2.1) Assuming a maximum displacement $d_{\mathrm{Bm}}{ }^{*}$ of the equivalent SDOF system of the braced structure $\mathrm{EP}(\mathrm{S}$ $+\mathrm{DB})$, evaluated in correspondence of the Basic Design Earthquake (BDE), the target ductility $\mu^{*}$ of the existing structure (S) is defined by

$$
\mu^{*}=\frac{d_{\mathrm{Bm}}{ }^{*}}{d_{\mathrm{y}}{ }^{*}} \leq \mu_{\mathrm{F}}^{*} .
$$

If the aim of the design is that the structure remains in elastic range $\left(\mu^{*}=1\right)$, then $d_{\mathrm{Bm}}{ }^{*} \leq d_{\mathrm{y}}{ }^{*}$. Otherwise, a limited inelastic capacity of the existing structure can be exploited, in that case $1<\mu^{*} \leq 1.5 \div 3$, for brittle or ductile mechanism, respectively, and then $d_{\mathrm{y}}{ }^{*}<$ $d_{\mathrm{Bm}}{ }^{*} \leq d_{\mathrm{u}}{ }^{*}$.

(2.2) Assuming a design ductility $\mu_{\mathrm{DB}}$ of the equivalent SDOF of the bracing system (DB), the optimal ductility values range between 4 and 12 , consistently with the properties of the considered hysteretic device and the Serviceability Design Earthquake (SDE) $[7,8,28$, 29]. Those values refer to the in series composition 


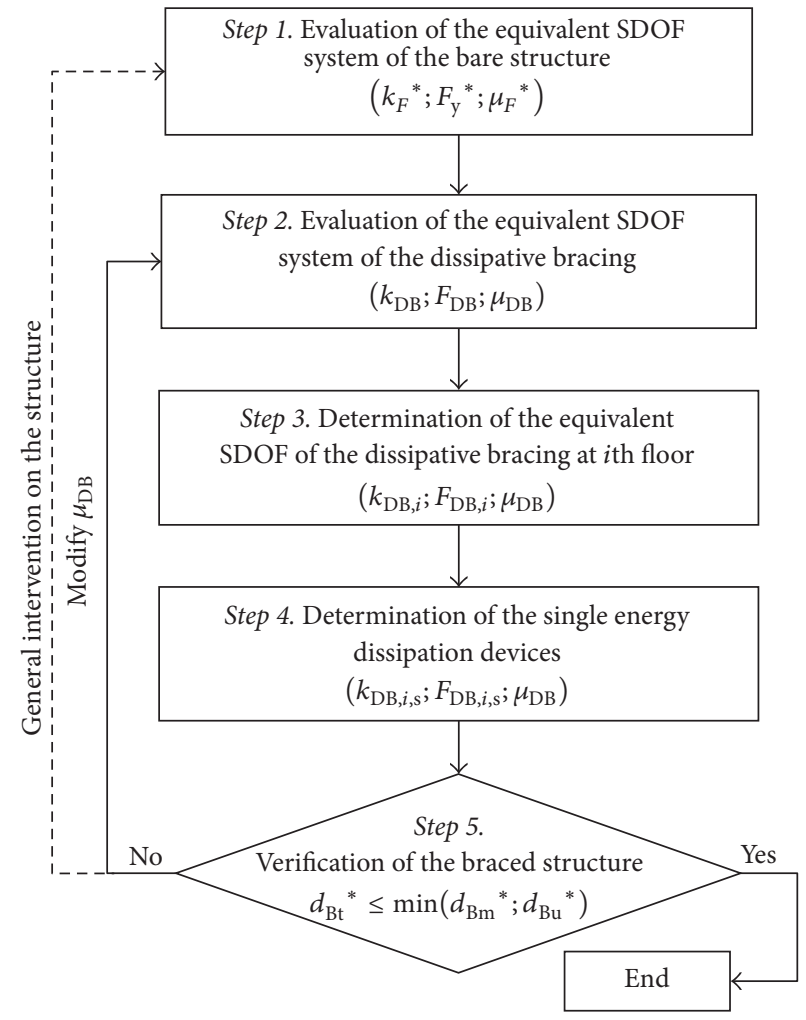

(a)

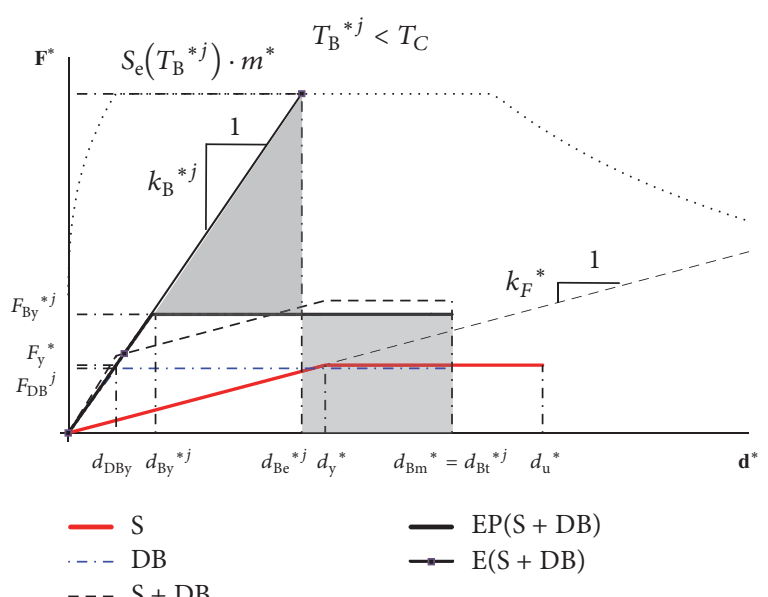

(A)

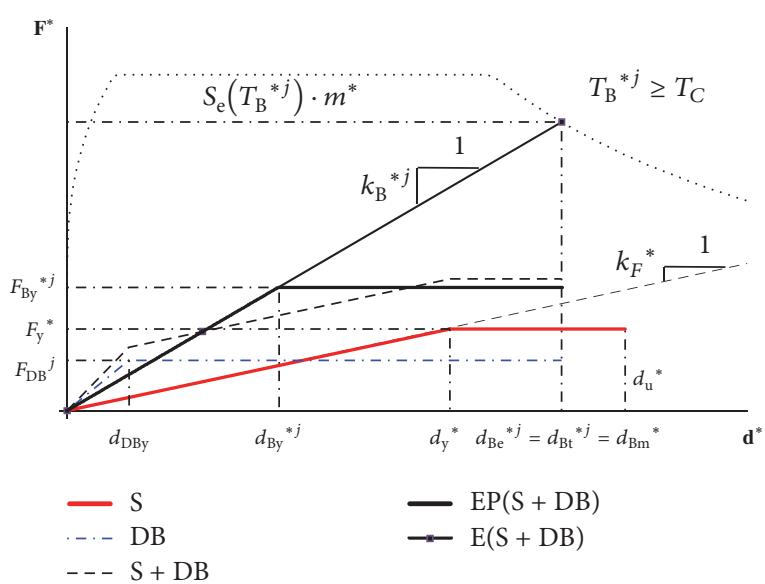

(B)

(b)

Figure 1: (a) Design procedure; (b) Step 2 for (A) short-period range; (B) medium/long-period range.

of the Hysteretic Damper (HD) and the rigid bracing truss (R). They allow the devices for responding elastically at the Serviceability Design Earthquake (SDE) and with a nonlinear behaviour at BDE.

The ultimate displacement of the equivalent bracing $d_{\mathrm{DBu}}$ is assumed to be equal to the maximum displacement $d_{\mathrm{Bm}}{ }^{*}$, and then the yield displacement of the equivalent SDOF of the bracing system (DB) $d_{\mathrm{DBy}}$ is given by

$$
d_{\mathrm{DBy}}=\frac{d_{\mathrm{Bm}}{ }^{*}}{\mu_{\mathrm{DB}}} .
$$

(2.3) The yield force $F_{\mathrm{DB}}{ }^{j}$ of the equivalent SDOF of damped bracing (DB) system at the $j$ th step is the unknown of the procedure. The elastic stiffness of the DB system $k_{\mathrm{DB}}{ }^{j}$ is determined by

$$
k_{\mathrm{DB}}^{j}=\frac{F_{\mathrm{DB}}{ }^{j}}{d_{\mathrm{DBy}}} .
$$

The trilinear curve $\mathrm{S}+\mathrm{DB}$ is obtained by summing in parallel the equivalent structure (S) and bracing system (DB). The equivalent period $T_{\mathrm{B}}{ }^{* j}$ and the elastic displacement $d_{\mathrm{Be}}{ }^{* j}$ of the equivalent SDOF system of the braced structure $(\mathrm{EP}(\mathrm{S}+\mathrm{DB}))$ are evaluated by $(4)$ (see Figure 1(b)), where the elastic stiffness $k_{\mathrm{B}}{ }^{* j}$ and yield force $F_{\mathrm{By}}{ }^{* j}$ of the equivalent $(\mathrm{EP}(\mathrm{S}+\mathrm{DB}))$ are determined by the idealized elastoplastic of the braced structure $(\mathrm{S}+\mathrm{DB})$.

$$
\begin{aligned}
T_{\mathrm{B}}{ }^{* j} & =2 \pi \sqrt{\frac{m^{*}}{k_{\mathrm{B}}{ }^{* j}}} ; \\
d_{\mathrm{Be}}{ }^{* j} & =S_{\mathrm{e}}\left(T_{\mathrm{B}}{ }^{* j}\right) \cdot\left[\frac{T_{\mathrm{B}}{ }^{* j}}{2 \pi}\right]^{2} .
\end{aligned}
$$

(2.4) At the $j$ th step, the target displacement $d_{\mathrm{Bt}}{ }^{* j}$ for the equivalent $(\mathrm{EP}(\mathrm{S}+\mathrm{DB}))$ of the Basic Design Earthquake $(\mathrm{BDE})$ is determinate as function of the 
period of the braced structure $T_{\mathrm{B}}{ }^{* j}$ and $T_{C}$ the upper limit of the period of the constant spectral acceleration branch $[24,25]$, as follows:

(1) If $T_{\mathrm{B}}{ }^{* j}<T_{C}$ short-period range, then $d_{\mathrm{Bt}}{ }^{* j}$ is determined from the equal energy criteria between the elastic $(\mathrm{E}(\mathrm{S}+\mathrm{DB}))$ and elastoplastic SDOF of the braced structure $(\mathrm{EP}(\mathrm{S}+\mathrm{DB}))$. Then, $d_{\mathrm{Bt}}{ }^{* j}$ can be expressed as the equality of the area underlying the elastic and elastoplastic oscillator curves; see Figure 1(b)(A).

Generally, the target displacement evaluated by equal energy criteria results more conservative than the displacement evaluated by NLSA [24, $25]$; see Step 5. This conservative design assumption is due to the stiffening effect of bracing into the structural frames.

(2) If $T_{\mathrm{B}}{ }^{* j} \geq T_{\mathrm{C}}$ medium/long-period range, then $d_{\mathrm{Bt}}{ }^{* j}$ is determined from the equal displacement criteria between the elastic $(\mathrm{E}(\mathrm{S}+\mathrm{DB}))$ and elastoplastic $(\mathrm{EP}(\mathrm{S}+\mathrm{DB}))$ oscillators of the braced structure; that is, $d_{\mathrm{Bt}}{ }^{* j}=d_{\mathrm{Be}}{ }^{* j}$; see Figure 1(b)(B).

If the target displacement $d_{\mathrm{Bt}}{ }^{* j}$ is much different from the maximum displacement $d_{\mathrm{Bm}}{ }^{*}$, bigger than an imposed tolerance value $\left|d_{\mathrm{Bt}}{ }^{* j}-d_{\mathrm{Bm}}{ }^{*}\right|>\varepsilon$, the iterative subroutine is applied. An updated value of the yielding force $F_{\mathrm{DB}}{ }^{j+1}$ of the equivalent DB system is evaluated and Substeps (2.3) and (2.4) are repeated. Usually the procedure converges in a few iterations.

Step 3 (determination of the characteristics of the equivalent dissipative bracing at storey $i$ ). The characteristics of the equivalent SDOF dissipating system, determined in the previous step, are distributed along the height of the building achieving the substantial satisfaction of the criteria of regularization in elevation for the braced structure, as defined by [25]. The distribution maximizes the efficiency of the bracing system and no single floor will exhibit excessive interstorey displacements. This should always be avoided in a regular building, as being connected to damage of structural and nonstructural elements and to the activation of weak or soft storey mechanism.

The stiffness $k_{\mathrm{BD}, i}$ of the equivalent bracing of the storey $i$ is determined hypothesizing that the ratio between the stiffness at each storey of the bare frame $k_{F, i}$ and that of the relative bracing $k_{\mathrm{DB}, i}$ is proportional to the ratio $r_{k}$ between the elastic stiffness of the equivalent bare structure $k_{F}{ }^{*}$ and the elastic stiffness of the bracing systems $k_{\mathrm{DB}}$, as shown by (5). The stiffness of the storey $i$ of the original structure $k_{F, i}$ can be calculated from the interstorey displacement $\Delta s_{i}$ generated by linear static analysis (LSA) applying a distribution of horizontal seismic forces $F_{i}$ to each storey.

$$
k_{\mathrm{DB}, i}=r_{k} \cdot k_{F, i}
$$

$$
\begin{aligned}
r_{k} & =\frac{k_{\mathrm{DB}}}{k_{F}{ }^{*}} \\
k_{F, i} & =\frac{1}{\Delta s_{i}} \cdot \sum_{i}^{n_{p}} F_{i} .
\end{aligned}
$$

In the case of irregular distribution in elevation of the stiffness of the retrofitted building at the end of the design procedure, the contribution of the bracing system in terms of stiffness has to be modified with the aim of regularizing the braced structure. To this end, reference is made to the criteria for regularity in elevation of the building set out in the codes $[24,25]$. The stiffness of equivalent bracing $k_{\mathrm{DB}, i}$ at the storey $i$ can be modified following the iterative procedure, valid for building having a number of storeys $n_{\mathrm{s}} \geq 2$, as reported in the following.

$$
\begin{aligned}
& \text { For } i=n_{\mathrm{s}}, \ldots, 2 \\
& \text { if } \Delta k_{\mathrm{tot}, i}{ }^{j}>0.3, \quad k_{\mathrm{DB}, i}{ }^{j}=m_{k} \cdot{k_{\mathrm{tot}, i-1}{ }^{j-1}-k_{F, i}} \\
& \text { if } \Delta k_{\mathrm{tot}, i}{ }^{j}<-0.1, \quad k_{\mathrm{DB}, i-1}{ }^{j}=\frac{k_{\mathrm{tot}, i}{ }^{j-1}}{M_{k}}-k_{F, i-1} \\
& \text { if }-0.1 \leq \Delta k_{\mathrm{tot}, i}{ }^{j} \leq 0.3, \\
& \qquad k_{\mathrm{DB}, i}{ }^{j}=k_{\mathrm{DB}, i}{ }^{j-1}, k_{\mathrm{DB}, i-1}{ }^{j}=k_{\mathrm{DB}, i-1}{ }^{j-1},
\end{aligned}
$$

where $\Delta k_{\mathrm{tot}, i}=\left(k_{\mathrm{tot}, i-1}-k_{\mathrm{tot}, i}\right) / k_{\mathrm{tot}, i-1}$ is the variation of the stiffness of the reinforced structure at the $i$ th storey respect lower floor; $k_{\mathrm{tot}, i}=k_{F, i}+k_{\mathrm{DB}, i}$ is the stiffness of the $i$ th storey of the braced structure; $m_{k}$ and $M_{k}$ are the stiffness correction factors to be taken in the following range of values $0.7 \leq m_{k}<$ 1 and $1.1 \geq M_{k}>1 ; j=1, \ldots, n_{s}$ is the step of iteration.

In the same way, the yield force $F_{\mathrm{DB}, i}$ of the equivalent bracing at the $i$ th storey is determined in the hypothesis that the ratio between the yield force at each floor of the bare frame $F_{\mathrm{y}, i}$ and that of relative bracing $F_{\mathrm{DB}, i}$ is distributed proportionally to the ratio $r_{F}$ between the strength of equivalent bare structure $F_{\mathrm{y}}{ }^{*}$ and the strength of equivalent bracing $F_{\mathrm{DB}}$ systems (see (7)). The yield force $F_{\mathrm{y}, i}$ of the $i$ th storey of the bare structure can be calculated in a simplified manner starting from the displacements at the elastic limits $d_{\mathrm{y}, i}$ determined by redistributing the displacement at elastic limit of the original structure $d_{\mathrm{y}}{ }^{*}$ as a function of the ratio between the interstorey displacement $\Delta s_{i}$ and the total elastic displacement $s_{\text {TOT }}$ calculated by means of LSA.

$$
\begin{aligned}
F_{\mathrm{DB}, i} & =r_{F} \cdot F_{\mathrm{y}, i} ; \\
r_{F} & =\frac{F_{\mathrm{DB}}}{F_{\mathrm{y}}{ }^{*}} ; \\
F_{\mathrm{y}, i} & =k_{F, i} \cdot d_{\mathrm{y}, i} ; \\
d_{\mathrm{y}, i} & =\frac{\Delta s_{i}}{s_{\mathrm{TOT}}} \cdot d_{\mathrm{y}}{ }^{*} .
\end{aligned}
$$

When the ratio among the actual storey resistance of the bare frame and the resistance required by the analysis of 
the reinforced building varies nonproportionally (more than $20 \%$ ) between adjacent storeys, the yield force $F_{\mathrm{DB}, i}$ of storey $i$ of equivalent bracing system could be modified following the iterative procedure, valid for building having a number of storeys $n_{\mathrm{s}} \geq 3$, reported in the following.

For $i=2, \ldots, n_{\mathrm{s}}-1$

$$
\begin{aligned}
& \text { if } \Delta \rho_{i}{ }^{j}<0.8, \\
& \qquad F_{\mathrm{DB}, i}{ }^{j}=m_{F} \cdot\left(F_{\mathrm{y}, i-1}+F_{\mathrm{DB}, i-1}{ }^{j-1}\right) \cdot \frac{V_{\mathrm{Ed}, i}}{V_{\mathrm{Ed}, i-1}}-F_{\mathrm{y}, i} \\
& \text { if } \Delta \rho_{i}{ }^{j}>1.2, \\
& F_{\mathrm{DB}, i}{ }^{j}=M_{F} \cdot\left(F_{\mathrm{y}, i-1}+F_{\mathrm{DB}, i-1}{ }^{j-1}\right) \cdot \frac{V_{\mathrm{Ed}, i}}{V_{\mathrm{Ed}, i-1}}-F_{\mathrm{y}, i}
\end{aligned}
$$

if $0.8 \leq \Delta \rho_{i}{ }^{j} \leq 1.2, \quad F_{\mathrm{DB}, i}{ }^{j}=F_{\mathrm{DB}, i}{ }^{j-1}$,

where $\Delta \rho_{i}=\left(\rho_{i} / \rho_{i-1}\right)$ is the variation of the ratio $\rho$ at the $i$ th floor respect lower floor; $\rho_{i}=\left(F_{\mathrm{y}, i}+F_{\mathrm{DB}, i} / V_{\mathrm{Ed}, i}\right)>1$ is the ratio between storey resistance of the bare frame and resistance required by the analysis of the reinforced structure at the $i$ th floor; $V_{\mathrm{Ed}, i}$ is the design shear force of storey $i$ required by the analysis of the reinforced structure; $m_{F}$ and $M_{F}$ are the strength correction factors to be taken in the following range of values $0.8 \leq m_{F}<1$ and $1.2 \geq M_{F}>1$, from small to large irregularities in elevation of the original structure; $j=$ $1, \ldots, n_{\mathrm{s}}$ is the step of iteration.

In framed buildings, the stiffness and strength variations should not vary disproportionately between adjacent storeys. In the design of the dissipative bracing system, the corrections factors have been adopted in order to reduce the irregularities in elevation of the original structure and to contain the variation of stiffness and strength of the braced structure in the following range of values $-10 \%<\Delta k_{\text {tot }, i}<30 \%$ and $-20 \%<\Delta \rho_{i}<20 \%$, respectively.

Step 4 (determination of the single energy dissipation device). The characteristics of the single dissipating brace $\left(k_{\mathrm{DB}, i, s}, F_{\mathrm{DB}, i, s}, \mu_{\mathrm{DB}}\right)$ are finally defined starting from the equivalent dissipative bracing system of $i$ th storey, as function of the number and slope of the braces [20], as in the following:

$$
\begin{aligned}
& k_{\mathrm{DB}, i, s}=\frac{k_{\mathrm{DB}, i}}{n_{\mathrm{DB}, i}} \cdot \frac{1}{\cos ^{2} \phi_{s}} ; \\
& F_{\mathrm{DB}, i, s}=\frac{F_{\mathrm{DB}, i}}{n_{\mathrm{DB}, i}} \cdot \frac{1}{\cos \phi_{s}},
\end{aligned}
$$

where $n_{\mathrm{DB}, i}$ is the number of damped braces in the floor; $\phi_{s}$ is the angle between the single brace and the horizontal.

The preliminary design of the bracing elements is based on the yielding forces of the dissipative damper. Increased reliability is required for the dissipative bracing system. This shall be affected by applying a magnification factor $\gamma_{x}=$ 1.2 on the yielding forces of each dissipative damper unit to avoiding either any buckling phenomena for compression condition or yielding in tension under the Maximum Considered Earthquake (MCE) loading, as defined by codes [24].
The stiffness and ductility characteristics of the single Hysteretic Damper (HD) depend on the stiffness $k_{\mathrm{R}, i, s}$ of the single rigid bracing truss $(\mathrm{R})$ at the storey $i$, as defined in

$$
\begin{aligned}
F_{\mathrm{DB}, i, s} & =F_{\mathrm{HD}, i, s} ; \\
K_{\mathrm{DB}, i, s} & =\frac{k_{\mathrm{HD}, i, s} \cdot k_{\mathrm{R}, i, s}}{k_{\mathrm{HD}, i, s}+k_{\mathrm{R}, i, s}} \\
\mu_{\mathrm{DB}} & =\frac{k_{\mathrm{HD}, i, s}+k_{\mathrm{R}, i, s} \cdot \mu_{\mathrm{HD}}}{k_{\mathrm{HD}, i, s}+k_{\mathrm{R}, i, s}},
\end{aligned}
$$

where $k_{\mathrm{HD}, i, s}, F_{\mathrm{HD}, i, s} \mu_{\mathrm{HD}}$ are the stiffness, the yield force, and the ductility of each Hysteretic Damper (HD).

Typically, the ductility of devices $\mu_{\mathrm{HD}}$ based on steel yielding can reach values greater than 20, displaying stable behaviour for an adequate number of cycles [35]. In order to dissipate a good amount of energy reaching adequate values of ductility demanded to dissipating devices, the rigid support will be chosen considering a stiffness ratio $k_{\mathrm{R}, i, s} / k_{\mathrm{HD}, i, s} \geq 2$.

Step 5 (verification of the braced structure). The design procedure ends with the verification of the braced structure for the BDE. NLSA have been performed considering the MDOF model, which includes the nonlinear behaviour of the dissipative brace elements. The iterative procedure stops if the target displacement $d_{\mathrm{Bt}}{ }^{*}$ of the braced structure, modified considering a transformation factor $\Gamma_{\mathrm{B}}$ and the equivalent mass $m_{\mathrm{B}}{ }^{*}$, satisfies the condition of

$$
d_{\mathrm{Bt}}{ }^{*} \leq \min \left(d_{\mathrm{Bm}}{ }^{*} ; d_{\mathrm{Bu}}{ }^{*}\right),
$$

where

$$
\begin{array}{ll}
d_{\mathrm{Bt}}{ }^{*}=\frac{d_{\mathrm{Be}}{ }^{*}}{q_{\mathrm{B}}{ }^{*}}\left[1+\left(q_{\mathrm{B}}{ }^{*}-1\right) \cdot \frac{T_{\mathrm{C}}}{T_{\mathrm{B}}{ }^{*}}\right] \geq d_{\mathrm{Be}}{ }^{*} & \text { if } T_{\mathrm{B}}{ }^{*}<T_{\mathrm{C}} \\
d_{\mathrm{Bt}}{ }^{*}=d_{\mathrm{Be}}{ }^{*} \text { if } T_{\mathrm{B}}{ }^{*} \geq T_{\mathrm{C}} . &
\end{array}
$$

$q_{\mathrm{B}}{ }^{*}=S_{\mathrm{e}}\left(T_{\mathrm{B}}{ }^{*}\right) \cdot m_{\mathrm{B}}{ }^{*} / F_{\mathrm{By}}{ }^{*}$ is the ratio between the acceleration in the braced structure with unlimited elastic behaviour and with limited strength $[24,25] ; d_{\mathrm{By}}{ }^{*}, d_{\mathrm{Bu}}{ }^{*}$ are the yield and the ultimate displacements of the braced structure; $\mu_{\mathrm{B}}^{*}=$ $\min \left(d_{\mathrm{Bm}}{ }^{*} ; d_{\mathrm{Bu}}{ }^{*}\right) / d_{\mathrm{By}}{ }^{*}$ is the ductile capacity of the braced structure.

If (11) is not satisfied, the iterative procedure of Step 2 is applied increasing the design ductility of the dissipative bracing $\mu_{\mathrm{DB}}$ in Substep (2.2) and/or assuming a maximum displacement equal to the target displacement $d_{\mathrm{Bt}}{ }^{*}$ determined in Step 5, instead of $d_{\mathrm{Bm}}{ }^{*}$ assumed in Substep (2.1).

Moreover, in case of verification not satisfied, specific intervention to the structural elements (beams, columns, and/or beam to column joints) could be required in order to increase the capacity of the bare frame and the procedure restart from Step 1.

It is worth noting that the application of the NLSA is allowed in the hypothesis that the requirements laid out in 


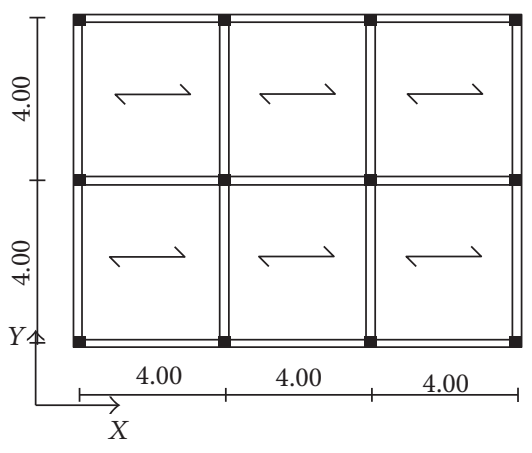

(a)

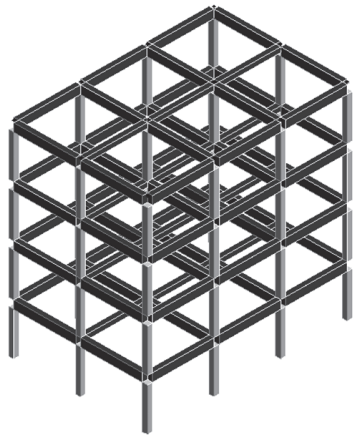

(b)

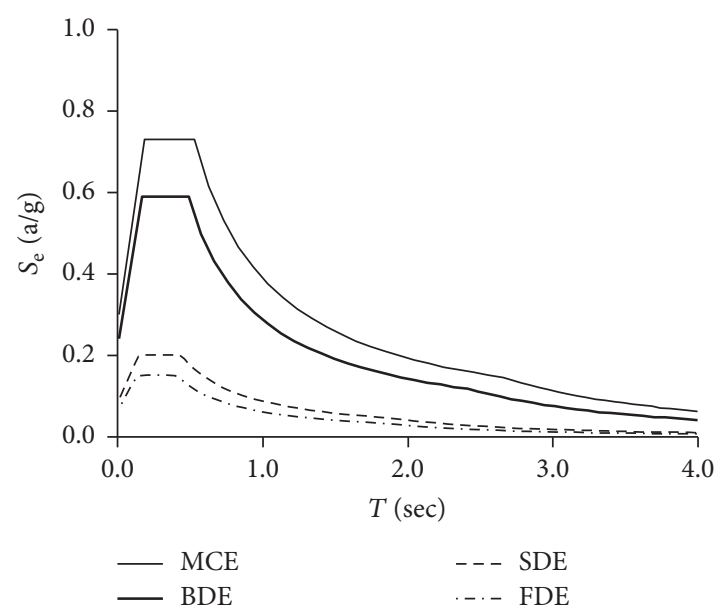

(c)

FIGURE 2: Benchmark structure: (a) plan view and (b) numerical model; (c) elastic response spectra.

TABLE 1: Details of cross section of the main structural elements.

\begin{tabular}{|c|c|c|c|c|c|c|c|}
\hline \multirow{2}{*}{ Element } & \multirow{2}{*}{$\begin{array}{c}\text { Cross section } \\
\mathrm{cm} \times \mathrm{cm}\end{array}$} & \multicolumn{4}{|c|}{ Longitudinal rebar } & \multicolumn{2}{|c|}{ Transversal rebar } \\
\hline & & \multicolumn{2}{|c|}{ 1st floor } & \multicolumn{2}{|c|}{2 nd-4th floor } & End of elem. & Middle of elem. \\
\hline \multirow[t]{4}{*}{ Column } & $30 \times 30$ & & $\phi 14$ & & & $\phi 6 / 15$ & $\phi 6 / 15$ \\
\hline & & \multicolumn{4}{|c|}{ 1st-4th floor } & & \\
\hline & & \multicolumn{2}{|c|}{ End } & \multicolumn{2}{|c|}{ Middle } & & \\
\hline & & Top & Bottom & Top & Bottom & & \\
\hline Beam & $30 \times 50$ & $4 \phi 14$ & $2 \phi 14$ & $2 \phi 14$ & $4 \phi 14$ & $\phi 6 / 15$ & $\phi 6 / 20$ \\
\hline
\end{tabular}

the codes for the use of this analysis method are respected (regularity criteria). As shown in the following, a correct positioning of the dissipating braces usually determines the achievement of regularity conditions. Otherwise, it should be necessary to perform a nonlinear dynamic analysis for the safety verification of the braced structure (Step 5).

\section{Application of the Design Procedure}

This section shows an example of application of the design procedure to a simple benchmark structure retrofitted with hysteretic EDBs. The example considers two different configurations of dissipative bracing shapes, namely, diagonal D and inverted $\mathrm{V}$, comparing the design performances with the results of NLDA.

3.1. Benchmark Structure. The benchmark structure considered in this simple example is a four-storey $\left(n_{s}=4\right)$ reinforced concrete framed building, with a rectangular plan, as showed in Figure 2(a). The structure represents an existing building located in the city of Potenza (Italy), classified as medium/high seismic area. The structure is founded on a soil type B and a topographic factor T1 [25] has been considered to evaluate the PGA ( $0.25 \mathrm{~g}$ for the Basic Design Earthquake (BDE)). The structure consists of three frames along the longitudinal direction $(X)$ and four frames in transverse direction $(Y)$. The interstorey height $h_{i}$ of all storeys is $3.0 \mathrm{~m}$. The cross sections of the main structural elements are described in Table 1. Structural elements have been designed by assuming the mechanical characteristics of materials coherently with a concrete type $R_{c k} 25$ and reinforcing steel FeB38k.

The benchmark structure has been modelled by using nonlinear finite element program CDS-Opensees [36]. Beams and columns have been modelled with elastic frame elements having nonlinear elastoplastic hinges concentrated at the ends. The hinges behaviour is based on the Takeda hysteretic model for the beams, for the columns it is axial loaddependent. The ultimate rotation depends on the amount and quality of the reinforcement rebar. The numerical models of the benchmark structure are shown in Figure 2(b). The elastic response spectra at different limit states for equivalent viscous damping ratio $\xi=5 \%$ are shown in Figure 2(c): Frequent Design Earthquake (FDE); Serviceability Design Earthquake (SDE); Basic Design Earthquake (BDE); Maximum Considered Earthquake (MCE).

The main characteristics of each storey of the bare structure, obtained by using LSA, are reported for both main directions in Table 2 in terms of seismic mass $m_{i}$, elastic stiffness $k_{F, i}$, yield force $F_{\mathrm{y}, i}$, and first normalized modal displacement $u_{i}$. It is possible to observe that the bare frames satisfy the criteria of structural regularity (stiffness and mass variation).

3.2. Design of the Hysteretic EDB Systems. The benchmark structure has been retrofitted by means of hysteretic EDB 
TABLE 2: Main characteristics of each storey of the bare structure.

\begin{tabular}{|c|c|c|c|c|c|c|c|c|c|c|}
\hline \multirow[b]{2}{*}{ Storey } & \multirow{2}{*}{$\begin{array}{l}\text { Interstorey } \\
\text { height } h_{i} \\
(\mathrm{~m})\end{array}$} & \multirow{2}{*}{$\begin{array}{c}\text { Seismic mass } \\
m_{i} \\
(\mathrm{t})\end{array}$} & \multicolumn{4}{|c|}{ Direction $X$} & \multicolumn{4}{|c|}{ Direction $Y$} \\
\hline & & & $\begin{array}{c}F_{\mathrm{y}, i} \\
(\mathrm{kN})\end{array}$ & $\begin{array}{c}k_{F, i} \\
(\mathrm{kN} / \mathrm{mm}) \\
\end{array}$ & $\begin{array}{c}\Delta k_{F, i} \\
\%\end{array}$ & $u_{i}$ & $\begin{array}{c}F_{\mathrm{y}, i} \\
(\mathrm{kN})\end{array}$ & $\begin{array}{c}k_{F, i} \\
(\mathrm{kN} / \mathrm{mm})\end{array}$ & $\begin{array}{c}\Delta k_{F, i} \\
\%\end{array}$ & $u_{i}$ \\
\hline 1st & 3.1 & 115 & 325 & 44 & 20 & 0.31 & 360 & 49 & 18 & 0.31 \\
\hline 2nd & 6.2 & 115 & 287 & 35 & 0 & 0.64 & 317 & 40 & 3 & 0.64 \\
\hline $3 \mathrm{rd}$ & 9.3 & 115 & 206 & 35 & 6 & 0.88 & 228 & 39 & 8 & 0.88 \\
\hline 4 th & 12.4 & 86 & 95 & 33 & & 1.00 & 105 & 36 & & 1.00 \\
\hline
\end{tabular}

TABLE 3: Main properties of equivalent bare structure and equivalent braced system.

\begin{tabular}{lccccccccccc}
\hline Direction & $m^{*}$ & $T^{*}$ & $\begin{array}{c}\text { Step 1 } \\
S\left(T^{*}\right)\end{array}$ & $\begin{array}{c}F_{\mathrm{y}}{ }^{*} \\
(\mathrm{t})\end{array}$ & $\begin{array}{c}k_{F}{ }^{*} \\
(\mathrm{kNN})\end{array}$ & $\begin{array}{c}(\mathrm{a} / \mathrm{g}) \\
(\mathrm{kN})\end{array}$ & $\mu_{F}{ }^{*}$ & $\begin{array}{c}d_{\mathrm{Bm}}{ }^{*} \\
(\mathrm{~mm})\end{array}$ & $\mu^{*}$ & $\begin{array}{c}\mu_{\mathrm{DB}} \\
F_{\mathrm{DB}} \\
(\mathrm{kN})\end{array}$ & $\begin{array}{c}k_{\mathrm{DB}} \\
(\mathrm{kN} / \mathrm{mm})\end{array}$ \\
\hline$X$ & 296 & 0.92 & 0.31 & 324 & 14 & 1.9 & 36 & 1.5 & 4 & 357 \\
$Y$ & 296 & 0.87 & 0.33 & 360 & 15 & 1.8 & 37 & 1.5 & 4 & 320 \\
\hline
\end{tabular}

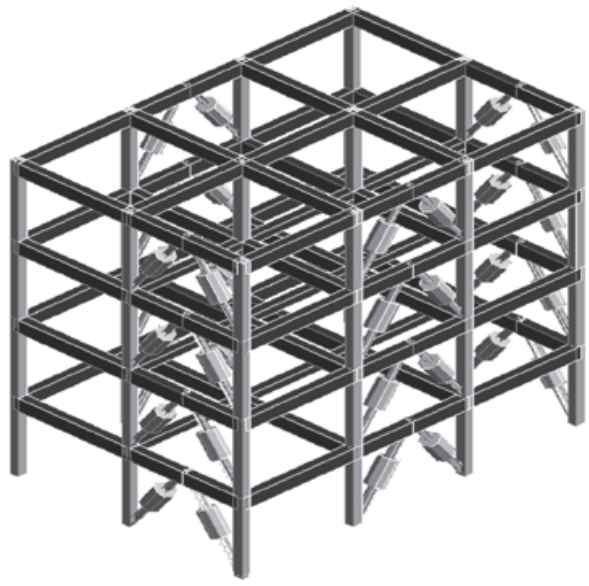

(a)

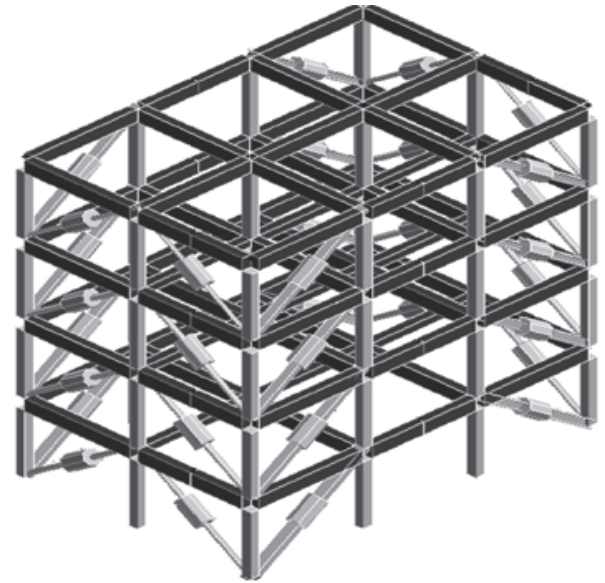

(b)

FIgURE 3: Numerical models of the braced structure, configuration: (a) inverted V and (b) diagonal D.

systems considering both inverted V (Figure 3(a)) and diagonal D (Figure 3(b)) configurations, suitably designed by using the design procedure described above.

The idealized SDOF systems of the bare structure (without retrofit) evaluated at the Step 1 are reported in Table 3 for both main directions (see also Figure 2(c)). The capacity curves of the bare structure are shown in Figures 4(a) and 4(c).

With the aim to limit the maximum interstorey drift of the braced structure at $0.5 \%$ under the BDE, a maximum displacement $d_{\mathrm{Bm}}{ }^{*}$ was established at Step 2, corresponding to a structure ductility equal to $\mu^{*}=1.5$, as considered by Italian code [25] for existing buildings. The design ductility of the equivalent dissipative bracing system was assumed $\mu_{\mathrm{DB}}=4$. The characteristics of the equivalent SDOF of the DB systems are reported in Table 3.

The stiffness $k_{\mathrm{DB}, i}$ and the yield force $F_{\mathrm{DB}, i}$ of the equivalent bracing systems at storey $i$ evaluated at Step 3 are reported in Table 4 . Moreover, Table 4 shows the stiffness $k_{\mathrm{HD}, i, s}$ and yield force $F_{\mathrm{HD}, i, s}$ of the single Hysteretic Damper HD obtained at Step 4. The HDs were evaluated assuming a ductility capacity of the dissipating devices $\left(\mu_{\mathrm{HD}}=20\right)$ and a rigid steel bracing trusses $\left(k_{\mathrm{R}, i, \mathrm{~s}} / k_{\mathrm{HD}, i, \mathrm{~s}} \approx\right.$ 2).

The Step 5 has been applied separately for both main directions considering the numerical models of the benchmark structure equipped with both configurations of nonlinear dissipative bracing configurations ( $\mathrm{D}$ and inverted V) as shown in Figures 4(b) and 4(d). The finite element software considered in this study uses specific elements to simulate the elastoplastic behaviour of the dissipative bracing systems.

Diagrams of Figure 4 clearly show the effectiveness of the retrofitting technique in reducing the target displacement of the centre of mass of the top floor. The values of the overall ductile capacity $\mu_{\mathrm{B}}{ }^{*}$ of the braced structure obtained with the considered intervention are equal to 2.8 and 2.5 in direction $X$ and $Y$, respectively. 

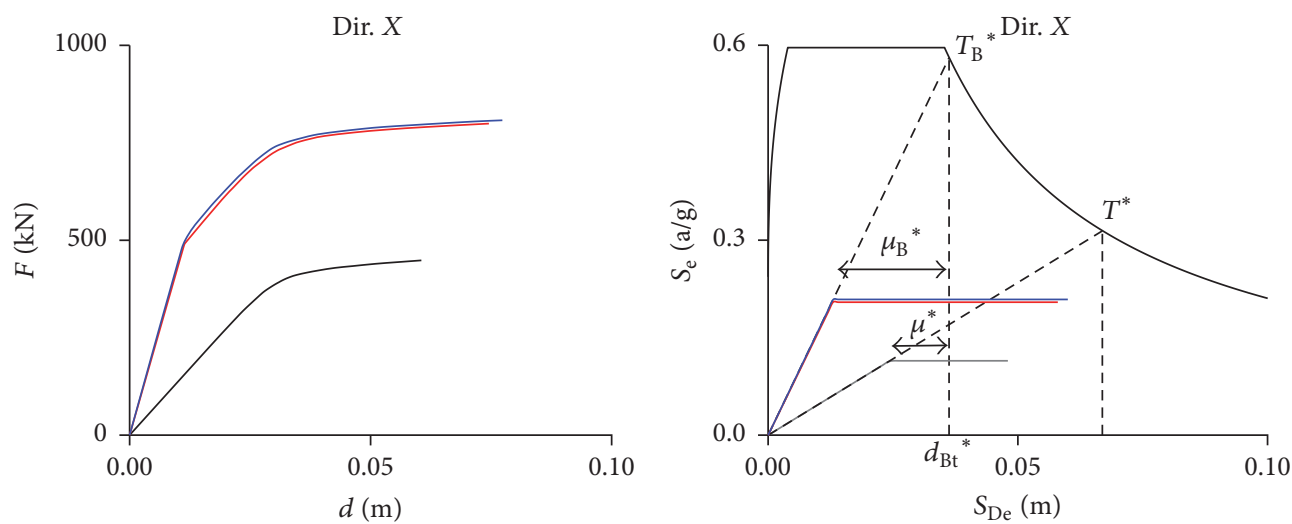

Bare structure
- Braced structure (D)
Braced structure (V)

(a)

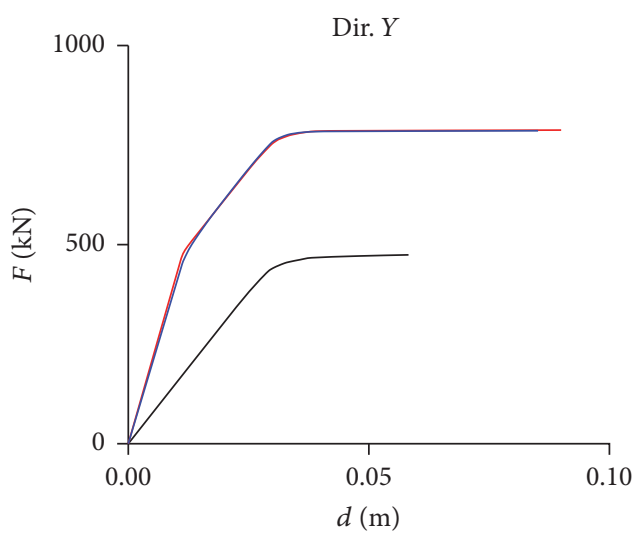

_ Bare structure

_ Braced structure (D)

_ Braced structure (V)

(c)

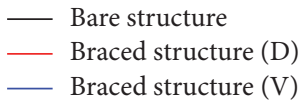

(b)

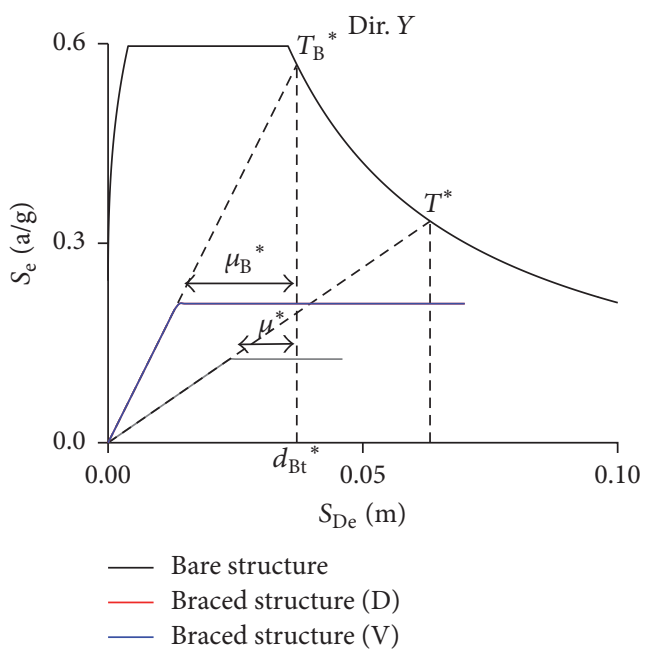

(d)

FIGURE 4: Comparison between pushover curves of the building with and without seismic retrofit: (a) direction $X$ and (c) direction $Y$; verification of upgraded structure using NTC08: (b) direction $X$ and (d) direction $Y$.

TABLE 4: Characteristics of the dissipative braces.

\begin{tabular}{|c|c|c|c|c|c|c|c|c|c|}
\hline \multirow{3}{*}{ Direction } & \multirow{3}{*}{ Storey } & \multicolumn{2}{|c|}{ Step 3} & \multicolumn{5}{|c|}{ Step 4} & \\
\hline & & \multirow{2}{*}{$\begin{array}{l}F_{\mathrm{DB}, i} \\
(\mathrm{kN})\end{array}$} & \multirow{2}{*}{$\begin{array}{c}k_{\mathrm{DB}, i} \\
(\mathrm{kN} / \mathrm{mm})\end{array}$} & \multicolumn{3}{|c|}{ Configuration inverted V } & \multicolumn{3}{|c|}{ Configuration D } \\
\hline & & & & $\begin{array}{l}\text { Rigid } \\
\text { truss }\end{array}$ & $\begin{array}{c}F_{\mathrm{HD}, i, s} \\
(\mathrm{kN})\end{array}$ & $\begin{array}{c}k_{\mathrm{HD}, i, s} \\
(\mathrm{kN} / \mathrm{mm})\end{array}$ & $\begin{array}{l}\text { Rigid } \\
\text { truss }\end{array}$ & $\begin{array}{c}F_{\mathrm{HD}, i, s} \\
(\mathrm{kN})\end{array}$ & $\begin{array}{c}k_{\mathrm{HD}, i, s} \\
(\mathrm{kN} / \mathrm{mm})\end{array}$ \\
\hline \multirow{4}{*}{$X$} & 1st & 358 & 130 & HE $180 \mathrm{~A}$ & 165 & 165 & HE $140 \mathrm{~A}$ & 115 & 80 \\
\hline & 2nd & 316 & 103 & HE $160 \mathrm{~A}$ & 150 & 125 & HE $120 \mathrm{~A}$ & 100 & 60 \\
\hline & $3 \mathrm{rd}$ & 227 & 101 & HE $160 \mathrm{~A}$ & 100 & 120 & HE $120 \mathrm{~A}$ & 70 & 60 \\
\hline & 4 th & 104 & 98 & HE $140 \mathrm{~A}$ & 50 & 130 & HE $120 \mathrm{~A}$ & 40 & 60 \\
\hline \multirow{4}{*}{ Y } & 1 st & 320 & 111 & HE $180 \mathrm{~A}$ & 150 & 130 & HE $120 \mathrm{~A}$ & 100 & 60 \\
\hline & 2nd & 282 & 91 & HE $160 \mathrm{~A}$ & 130 & 110 & HE $100 \mathrm{~A}$ & 90 & 45 \\
\hline & $3 \mathrm{rd}$ & 203 & 89 & HE $160 \mathrm{~A}$ & 100 & 100 & HE $100 \mathrm{~A}$ & 65 & 45 \\
\hline & 4 th & 94 & 81 & HE $140 \mathrm{~A}$ & 50 & 100 & Tube $114.3 \times 5$ & 30 & 40 \\
\hline
\end{tabular}




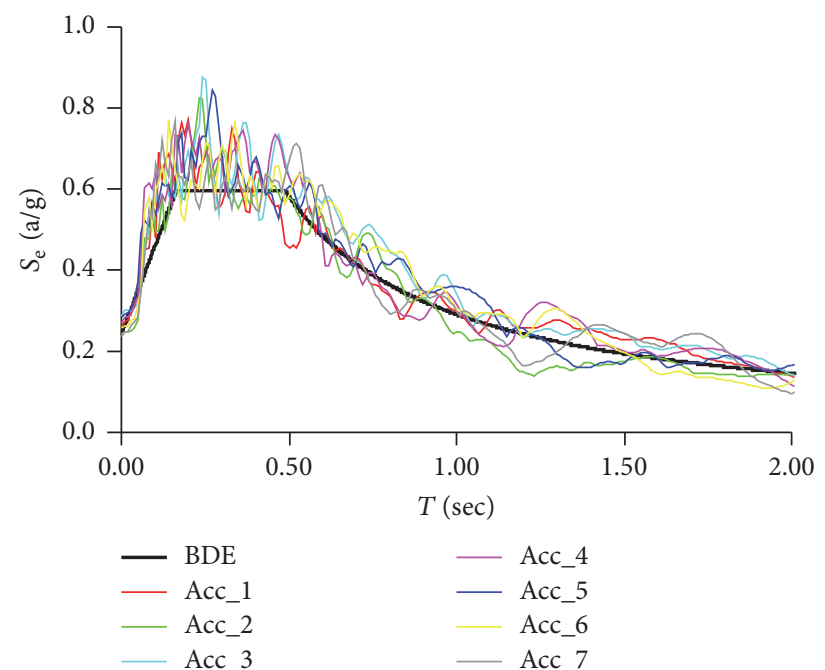

(a)

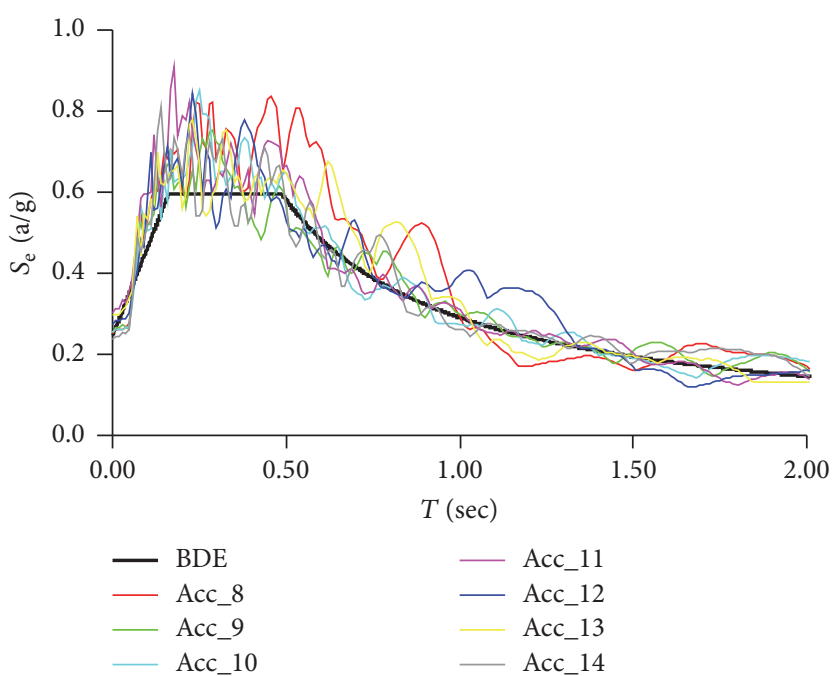

(b)

FIgURE 5: Sets of 7 accelerograms considered for the analysis in (a) direction $X$ and (b) direction $Y$.

3.3. Results of Nonlinear Dynamic Analyses. In order to estimate the maximum displacement of the braced structure (Step 5), bidirectional NLDA have been carried out considering a set of 7 artificial spectrum-compatible accelerograms matching, on average, the spectrum at the BDE adopted in the design procedure (see Figure 5). The $30 \mathrm{sec}$ accelerograms have been generated by CDS-Opensees [36]. They are characterized by a stationary part of $20 \mathrm{sec}$. In the range of periods between 0.15 and 2 seconds [25] no value of the mean 5\% viscous damping ratio, calculated from all time histories, is less than $90 \%$ of the corresponding value of the $5 \%$ viscous damping ratio of response spectrum.

The seismic response of the braced building has been evaluated by means of NLDA carried out with CDSOpensees, applying the accelerograms simultaneously in both directions.

Figure 6 shows the numerical results in terms of storey acceleration, interstorey drifts, and force-displacement cyclic behaviours of the HDs at all storeys. The diagrams refer to both bracing configurations ( $\mathrm{D}$ and inverted $\mathrm{V}$ ) subjected to earthquakes no. 1 and 8.

Time histories of drifts exhibit maximum value less than $0.4 \%$, which is comparable with the target drift $(0.5 \%)$ considered in the design procedure. Moreover, both configurations $\mathrm{D}$ and inverted $\mathrm{V}$ of bracing systems show analogous responses in terms of interstorey drifts and floor acceleration. The cyclic behaviour of devices, shown in Figure 6, highlights the activation of the energy dissipation braces at all storeys of the model with similar values of ductility demand (of about 3.5).

The NLDA averaged results in terms of maximum interstorey drifts of the benchmark structure, obtained considering all acceleration profiles, with and without EDB, are compared in Figure 7. Drift is commonly considered the main parameter to evaluate the performance of framed structures and the effectiveness of the retrofitting technique. As clearly shown by Figure 7 , the seismic response of the structure drastically decreases in amplitude when the EDBs are used; in fact a reduction of the maximum drift at all storeys of the braced model, corresponding to about 2-3 times with respect to that of the bare frame, has been observed. Referring to the diagrams of Figure 7 it should be highlighted that the values of the maximum interstorey drift could occur not at the same time step of the analysis.

In Figure 8 the capacity curves of the reinforced structures obtained by NLSA are compared with the results of NLDA. The curves have been generated for both principal directions using both uniform (mass) and modal (mode) distributions of horizontal forces $F_{i}$ at each storey. The output of NLDA, carried out considering all accelerograms, is expressed in terms of maximum top displacement versus the correspondent base shear. Figure 8 shows a good agreement between the mean value of the maximum displacements of the MDOF system and the maximum displacement $\left(d_{\mathrm{Bm}}{ }^{*} \cdot \Gamma_{\mathrm{B}}\right)$ of the control node, coinciding with the centre of mass of the top floor, considered in the design procedure.

\section{Estimation of Behaviour Factor of Braced Buildings}

It is worth noting that NLDA are not always simple to apply, especially for existing buildings, for several reasons: (i) difficulties in correctly modelling the actual characteristics of cyclic load-deformation of structural members (geometry and material uncertainties, cumulative damage, fatigue); (ii) the need to define a set of ground motions that would properly represent the seismic input at a given construction site; (iii) the longer computational time and other hindrances (complexity and accuracy).

For conventional reinforced concrete buildings the codes consider also the possibility of using linear analysis, in which 


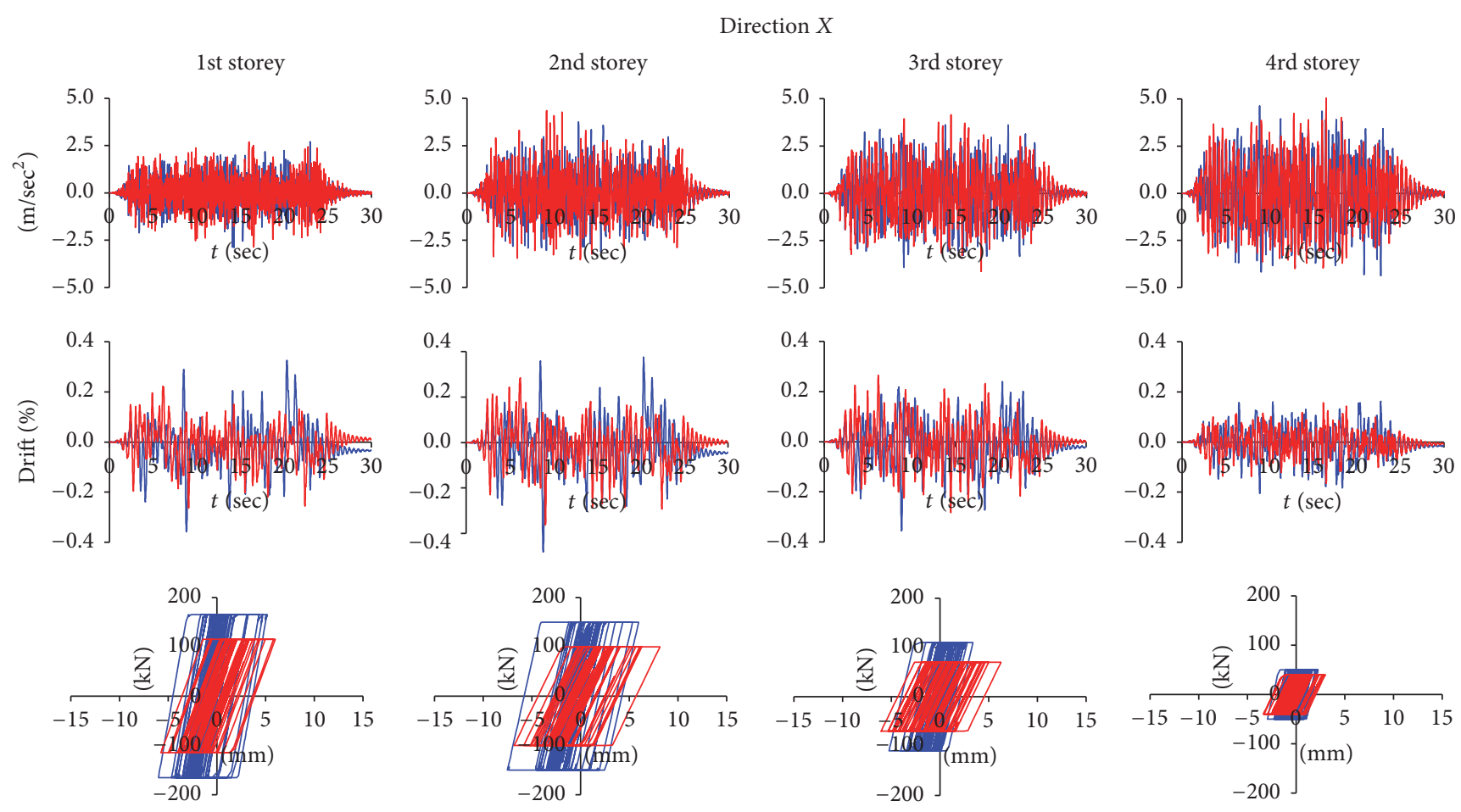

Direction $Y$
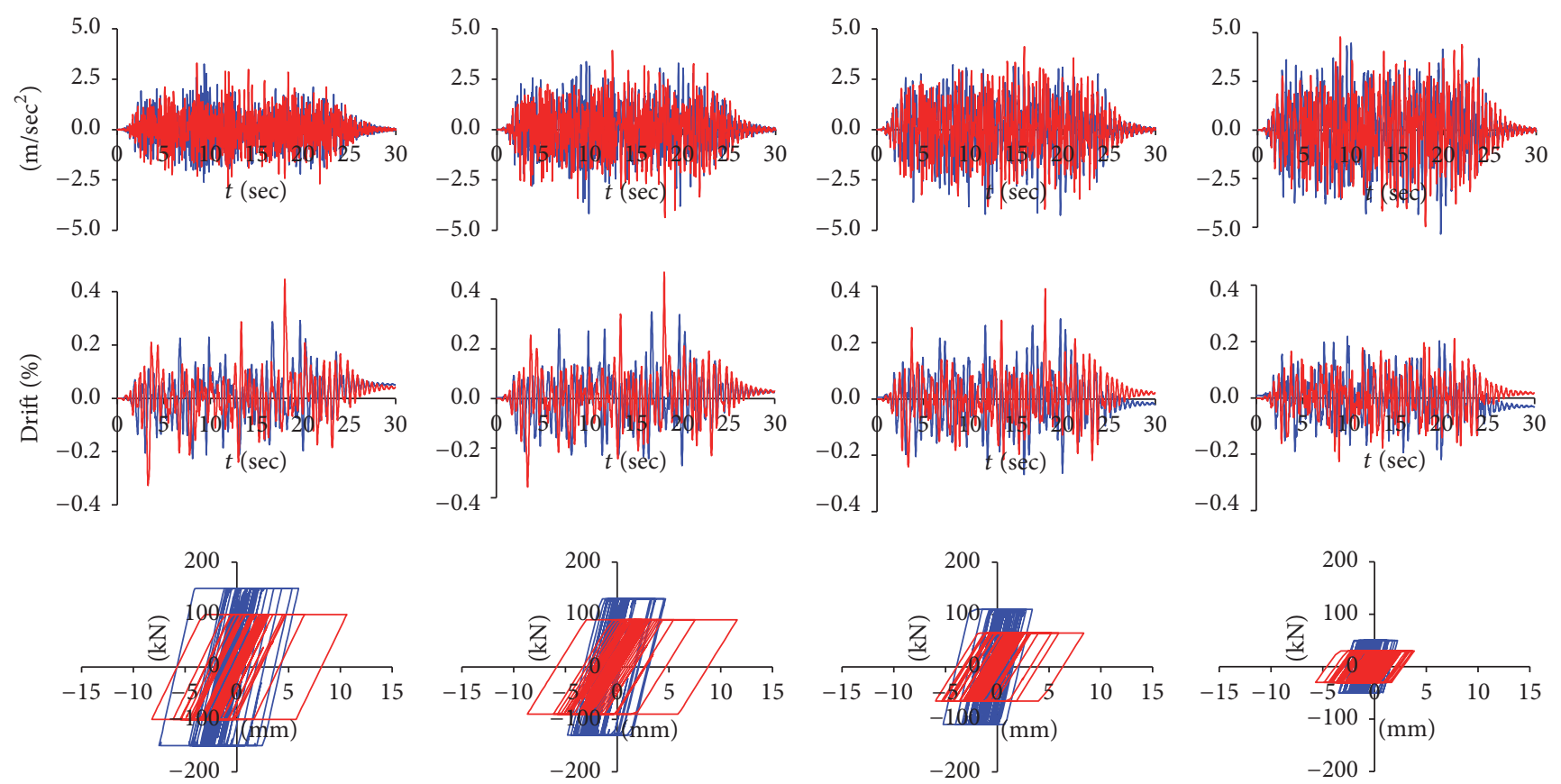

With retrofit $\mathrm{D}$
_ With retrofit $\mathrm{V}$

With retrofit $\mathrm{D}$
With retrofit $\mathrm{V}$

With retrofit $\mathrm{D}$
_ With retrofit $\mathrm{V}$

W With retrofit $\mathrm{D}$
_ With retrofit $\mathrm{V}$

Figure 6: Comparison of NLDA results considering earthquakes number 1 and number 8 for both directions of drift, acceleration, and force-displacement of the elastoplastic braces on both configurations of EDB (D and inverted V). 


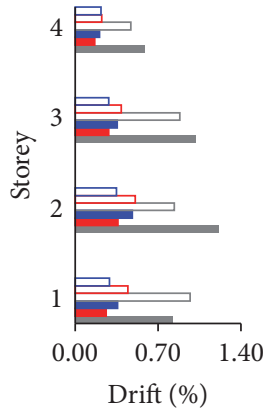

Acc 1-8

With retrofit_V Dir X With retrofit_V Dir $Y$
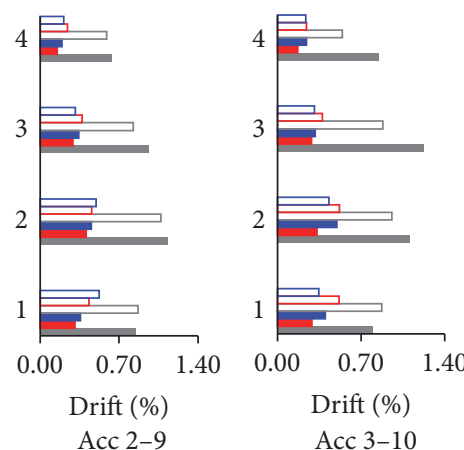

With retrofit_D Dir $X$ With retrofit_D Dir $Y$
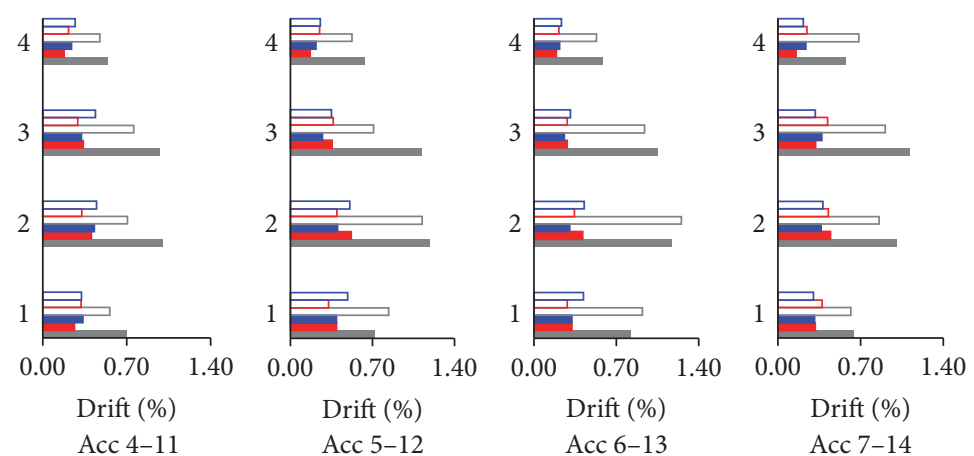

Without retrofit Dir $X$ Without retrofit Dir $Y$

FIGURE 7: Maximum drifts obtained by NLDA on model with and w/o damped bracing systems.
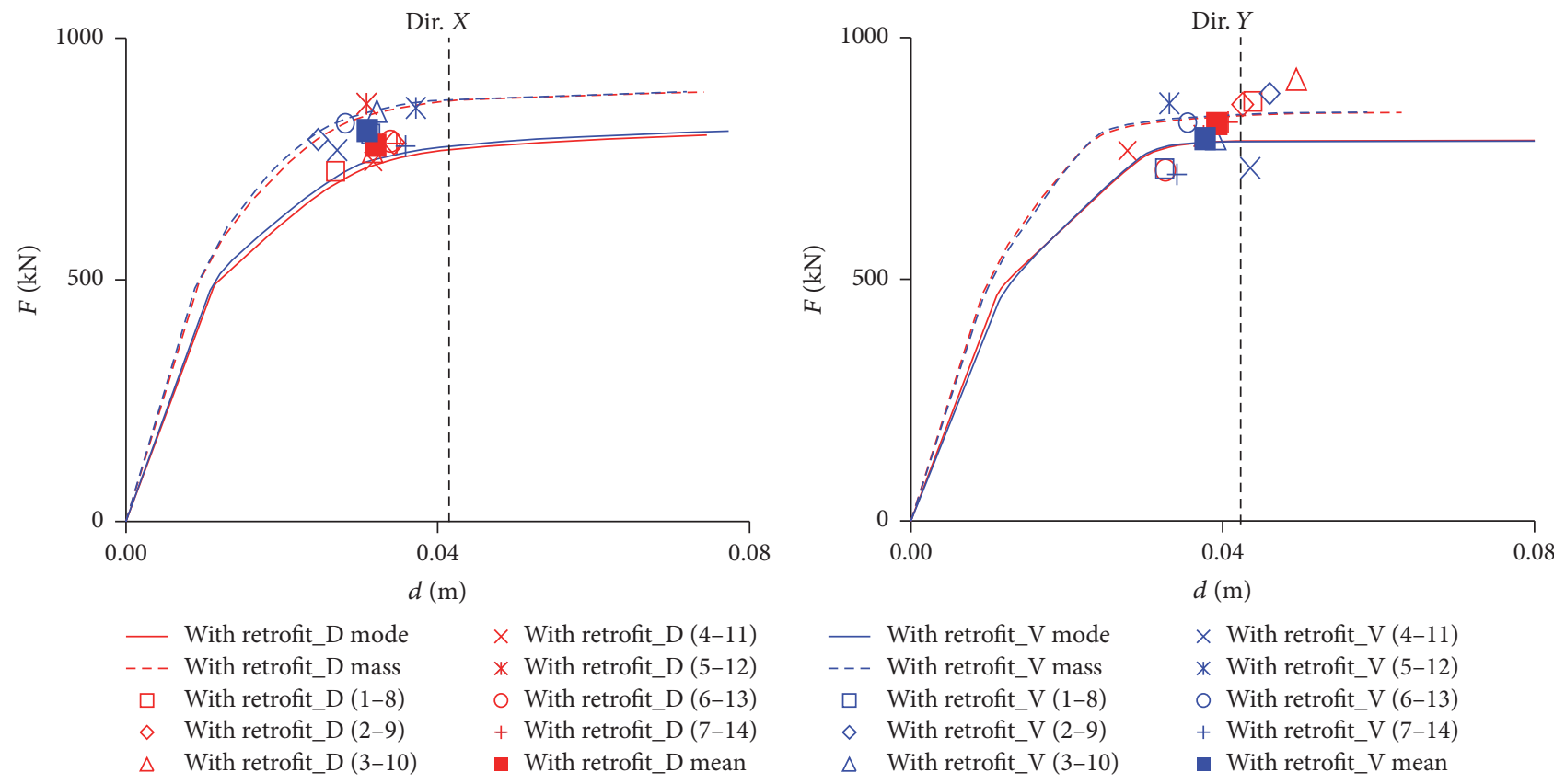

FIGURE 8: Comparison between the results of NLSA and the maximum top displacements versus base shears by NLDA.

the seismic demand (elastic spectrum) is suitably reduced by a behaviour factor $q$ [37], defined by codes [24, 25], as follows:

$$
q=q_{0} \cdot K_{w} \geq 1.5
$$

where $q_{0}$ is the basic value of the behaviour factor $q$, depending on structural type and on the ratio $\alpha_{\mathrm{u}} / \alpha_{1}$ between the collapse load multiplier $\left(\alpha_{\mathrm{u}}\right)$ and the multiplier for flexural yield $\left(\alpha_{1}\right) ; K_{w}$ is the factor reflecting the regular criteria in elevation of the building. It should reduce the behaviour factor $q$ by $20 \%$ for building which is not regular in elevation.

Following the guidance provided by the codes, NLSA may be applied in order to estimate the behaviour factor $q[38,39]$, as follows:

$$
\begin{aligned}
& q=1+\left(\mu_{d}-1\right) \cdot \frac{T_{1}}{T_{C}} \quad \text { if } T_{1}<T_{C} \\
& q=\mu_{d} \quad \text { if } T_{1} \geq T_{C},
\end{aligned}
$$

where $T_{1}$ is the fundamental period of the building; $\mu_{d}$ is the displacement ductility factor.

Several NLSA have been carried out considering all case studies in order to propose an analytical formulation of the behaviour factor $q_{\mathrm{B}}$ valid for braced buildings. The study aims to estimate a correction factor $C$ to increase the behaviour factor of the bare building $q$ (see (15)). The values of $q\left(T^{*}, \mu^{*}\right)$ and $q_{\mathrm{B}}\left(T_{\mathrm{B}}{ }^{*}, \mu_{\mathrm{B}}{ }^{*}\right)$ are evaluated by considering in (14) the values of $T^{*}$ and $\mu^{*}$ of the bare structure estimated by Step 1 of the design procedure and the values of $T_{\mathrm{B}}{ }^{*}$ and $\mu_{\mathrm{B}}{ }^{*}$ of the braced structure evaluated by Step 5 of the design procedure.

$$
C=\frac{q_{\mathrm{B}}\left(T_{\mathrm{B}}{ }^{*}, \mu_{\mathrm{B}}{ }^{*}\right)}{q\left(T^{*}, \mu^{*}\right)} \text {. }
$$

4.1. Case Studies. Twenty buildings representing the 1960s-1980s standard Italian constructions, designed for 


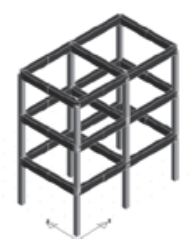

$1 \_3 s$

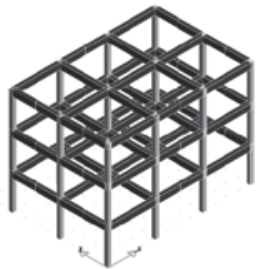

2_3s

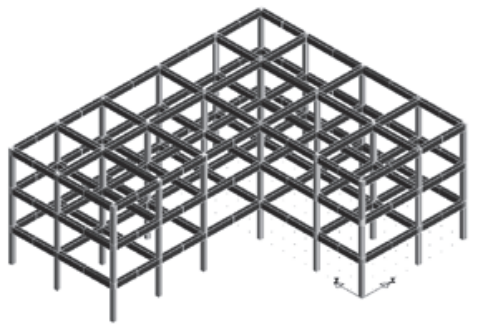

3_3s

(a)

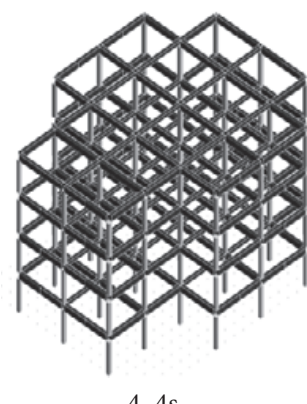

4_4s

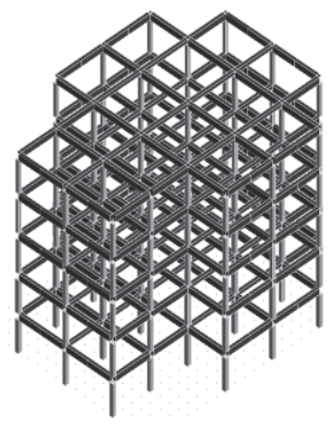

4 5s

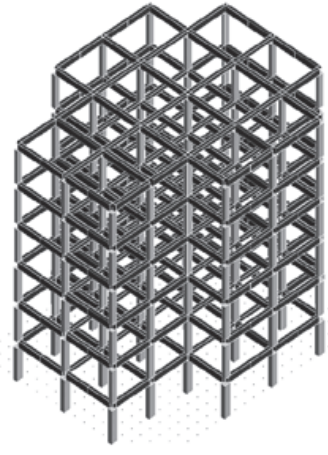

4 6s

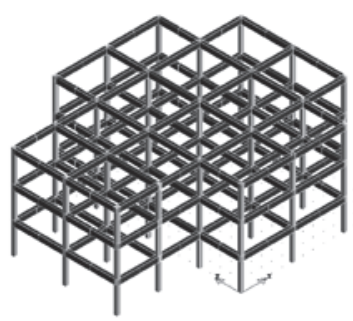

4_3s

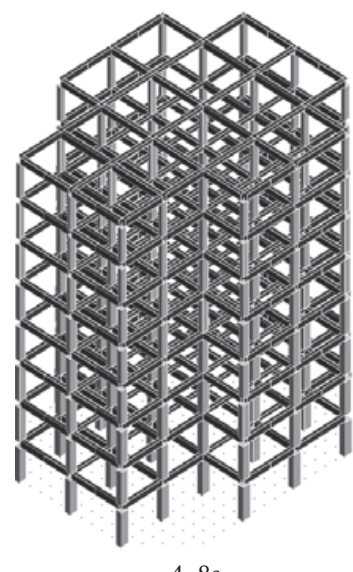

$4 \_8 s$

(b)

FIGURE 9: Numerical model of the bare structures: (a) 3 storey structural types and (b) different number of storeys of structural type 4.

vertical loads only, without considering seismic detailed rules, have been used for the statistical analysis. The buildings consisted of four different plans (two rectangles, one L shaped and one cruciform) with five values of number of storeys $(3,4,5,6$, and 8$)$. The beam and column dimensions and detailing were kept the same for all four types of structural plan. $R_{c k} 25$ concrete and FeB38k reinforcement steel were assumed as construction materials. The selected structures, without staircases, could represent individual units of complex buildings structures consisting of more than one dynamically independent unit, separated by structural joints. The structures have been modelled with CDS-Opensees [36]. The flexural and shear stiffness of the beam elements was reduced to $50 \%$ of the stiffness of the uncracked elements in order to account for cracking in concrete [24, 25]. On the contrary, the stiffness of the columns was not reduced due to the influence of permanent axial loading [40]. Infill panels were accounted only in terms of their weight $[15,31]$. In this study, brittle failures of structural elements (shear failure of beams and columns and failure of beam-column joints) or global mechanisms (soft storey due to a concentration of plastic hinges in columns of a single storey) have been accounted as prescribed the codes [24, 25].

Figure 9 shows the numerical models of the different types of bare structures considered in the study. The seismic action relating to the different limit states has been defined using the same elastic spectra considered for the benchmark structure (ID 2_4s, see Figure 5).

The design of the bracing systems has been performed for both directions of each bare structure. In Figure 10 the results of NLSA (Step 1) of all bare structures are compared with the $\mathrm{BDE}$. The braces were designed considering two different arrangements, inverted $\mathrm{V}$ and diagonal (D) systems, for 40 different case studies. In each case study the procedure was applied considering different design targets: (i) four values of target ductility $\mu^{*}$ of the existing structure (Substep (2.1)) corresponding to 1.0, 1.15, 1.3, and 1.5; (ii) three values of design ductility $\mu_{\mathrm{DB}}$ of dissipative bracing system (Substep (2.2)) equal to 4,8 , and 12, for a total of 960 analyses.

The numerical models of all type 3-storey $\left(n_{\mathrm{s}}=3\right)$ structures, considering both reinforcing bracing arrangements $(\mathrm{V}$ and D), are shown in Figure 11.

Several studies evaluated the optimum placement of various types of passive dampers in asymmetric buildings, mainly consisting of counterbalancing the eccentricity between the centre of mass and centre of stiffness of the braced structure. Most optimal distributions involved the incorporation of supplemental damping along the perimeter of the buildings $[6,41,42]$. According to this approach, the dissipating bracing systems have been deployed around the perimeter of the building and sized in a way that their centre of shear force 

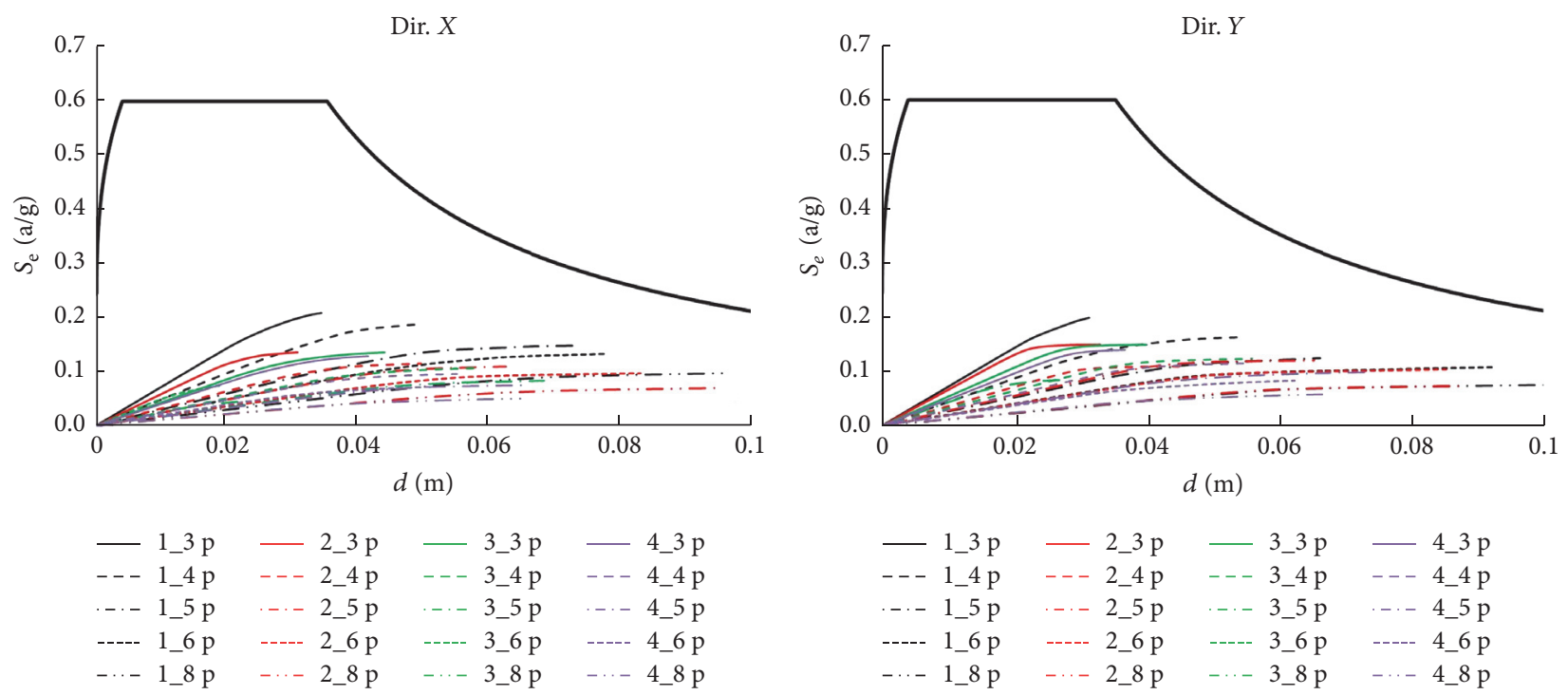

FIGURE 10: Pushover curves of the bare structures compared with the seismic demand (BDE).

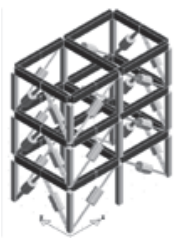

$1 \_3 s-D$

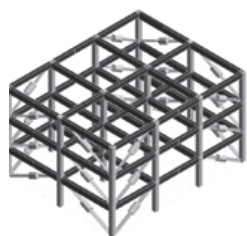

2_3s - D

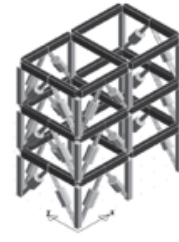

$1 \_3 s-$ V

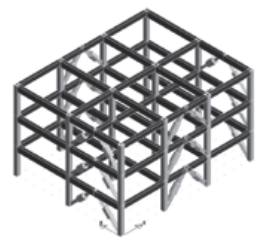

$23 s-V$

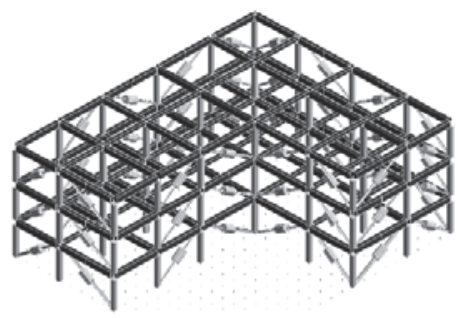

3_3s - D

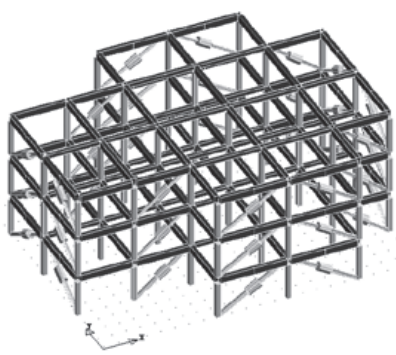

$4 \_3 s-D$

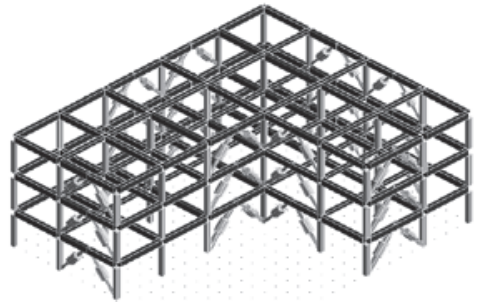

3_3s - V

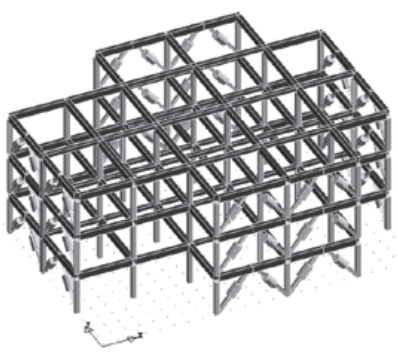

4_3s - V

FIGURE 11: Numerical models of different 3 storey structures braced with different configurations of EDBs (V and D).

has an equal but opposite eccentricity with respect to the centre of mass of the building. The number of braced frames is function of the yield force of the hysteretic dampers and the resistance of the structural elements and joints. In the cases studied the maximum yield force of HDs was assumed as $F_{\mathrm{HD}, i, s} \leq 600 \mathrm{kN}$. The specific effects of the regularization of an irregular real building with staircase, obtained by introducing supplemental bracing systems designed applying the proposed procedure, have been evidenced in [43].

The outcomes resulting from Step 5 for all case studied are summarized for both directions in Table 5 in terms of satisfaction of (11) ( $\mathrm{y}=$ verified items; $\mathrm{n}=$ not verified; $-=$ not considered). As can be seen, almost all structures have at least one case verified. It is possible to note that the solution for both configurations could be found reducing the ductility $\mu_{\mathrm{DB}}$ of the bracing system. The cases not considered in the Table 5 are those in which local reinforcements are required in order to lead to convergence of the procedure due to the limited strength of the structures compared to the reference seismic action. In order to uniform the results of the parametric analysis, this study did not consider any specific interventions to the structure elements (beams and/or columns) of the frames in which the bracing was applied. Moreover, the comparison between the results obtained considering two bracing configurations ( $\mathrm{D}$ and inverted $\mathrm{V}$ ) shows that almost the same results have been obtained. In any case, a proper strengthening of the structural elements would allow finding at least one solution of the design procedure. 
TABLE 5: Results of analysis on reinforced structures designed considering all cases Dir. X/Dir. $Y$.

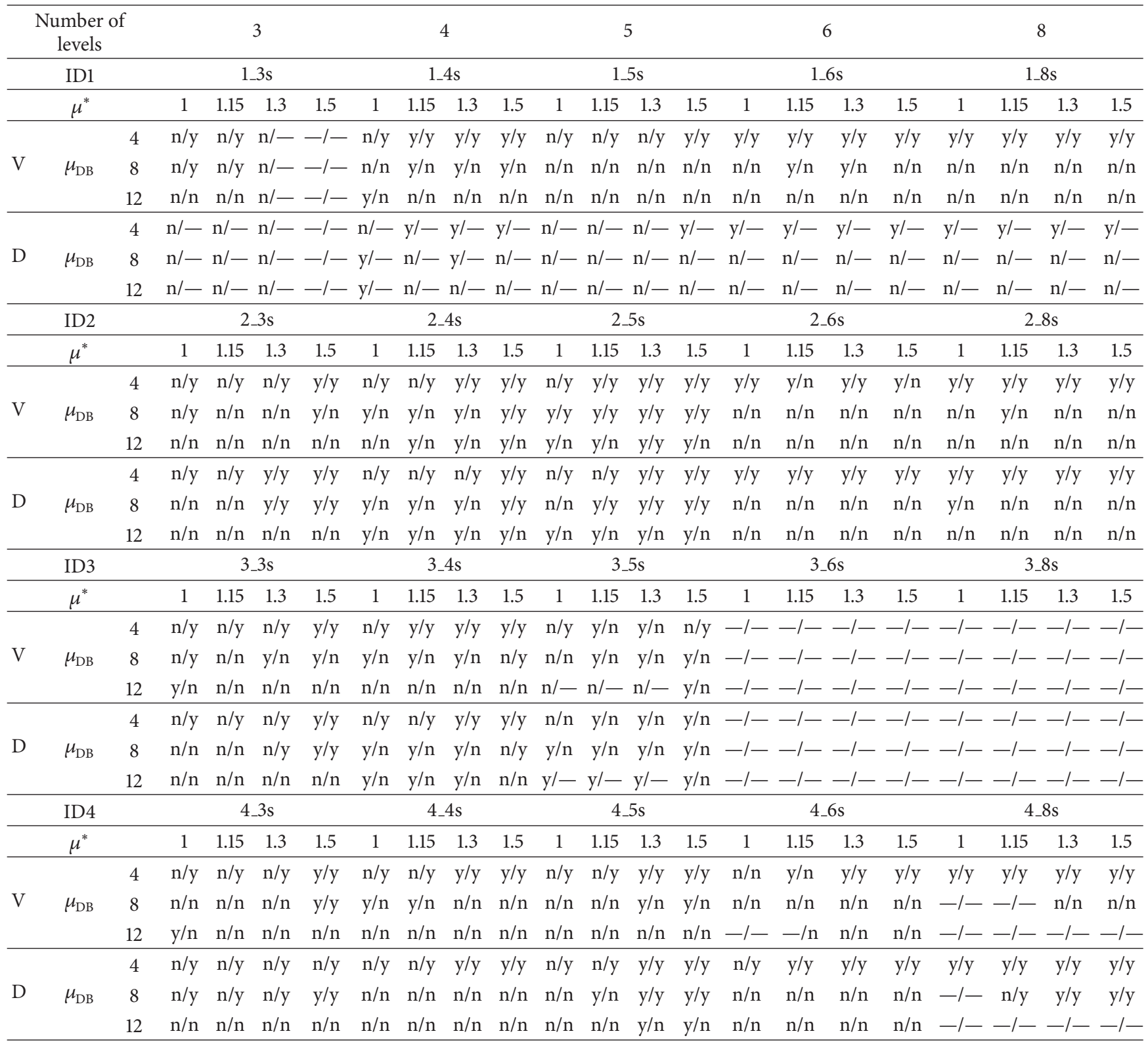

4.2. Influence of the Design Parameters. The correction factor $C$ of (15) has been evaluated for all cases, being verified or not, as shown in Figures 12 and 13. After that, a correlation between $C$ and the main structural parameters was sought, namely, $\mu^{*}, T_{\mathrm{B}}{ }^{*} / T^{*}, F_{\mathrm{DB}} / F_{\mathrm{y}}{ }^{*}, n_{\mathrm{s}}$, and $\mu_{\mathrm{DB}}$.

The outcomes of Figures 12 and 13 lead to the following considerations about the correction factor $C$ :

(i) it grows with the reduction of the ratio between the bilinear equivalent period of the braced structure $T_{\mathrm{B}}{ }^{*}$ and that of the bare structure $T^{*}$ (in the range of $0.2 \div$ $0.9)$;

(ii) it grows with the growth of the ratio between the yield force $F_{\mathrm{DB}}$ of the equivalent dissipative bracing system and the yield force $F_{\mathrm{y}}{ }^{*}$ of the equivalent bare structure (in the range of $0.2 \div 1.4$ ); (iii) there is no correlation with the value of number of storeys $n_{\mathrm{s}}$, almost for considered range $(3 \div 8$ story);

(iv) it seems almost independent from the value of design ductility $\mu_{\mathrm{DB}}$ of equivalent bracing system (in the range of $4 \div 12$ );

(v) it grows with decreasing of the target ductility $\mu^{*}$ of the bare structure (in the range of $1 \div 1.5$ );

(vi) it ranges from 1 to 4 for all combinations of the main design parameters.

4.3. Estimation of the Behaviour Factor. Based on the outcomes showed in the previous paragraph and with the aim of proposing a formulation to calculate the correction factor $C_{\text {cal }}$, a multiparameter linear regression analysis has been 

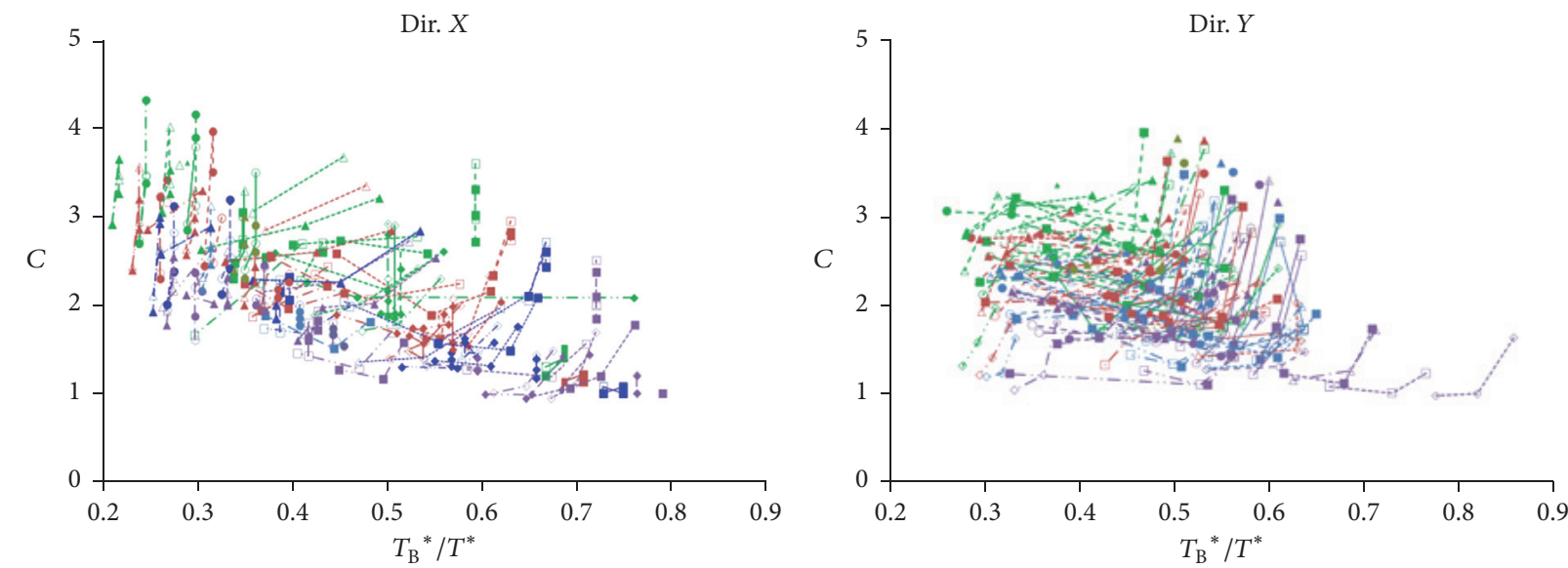

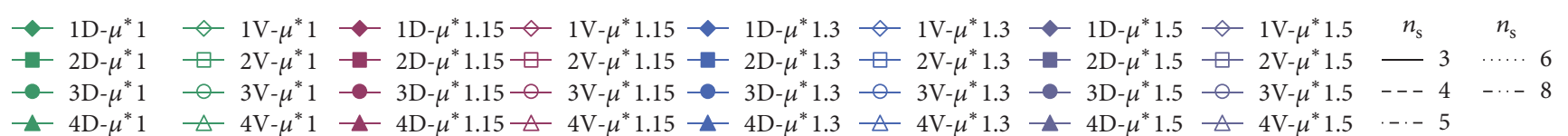
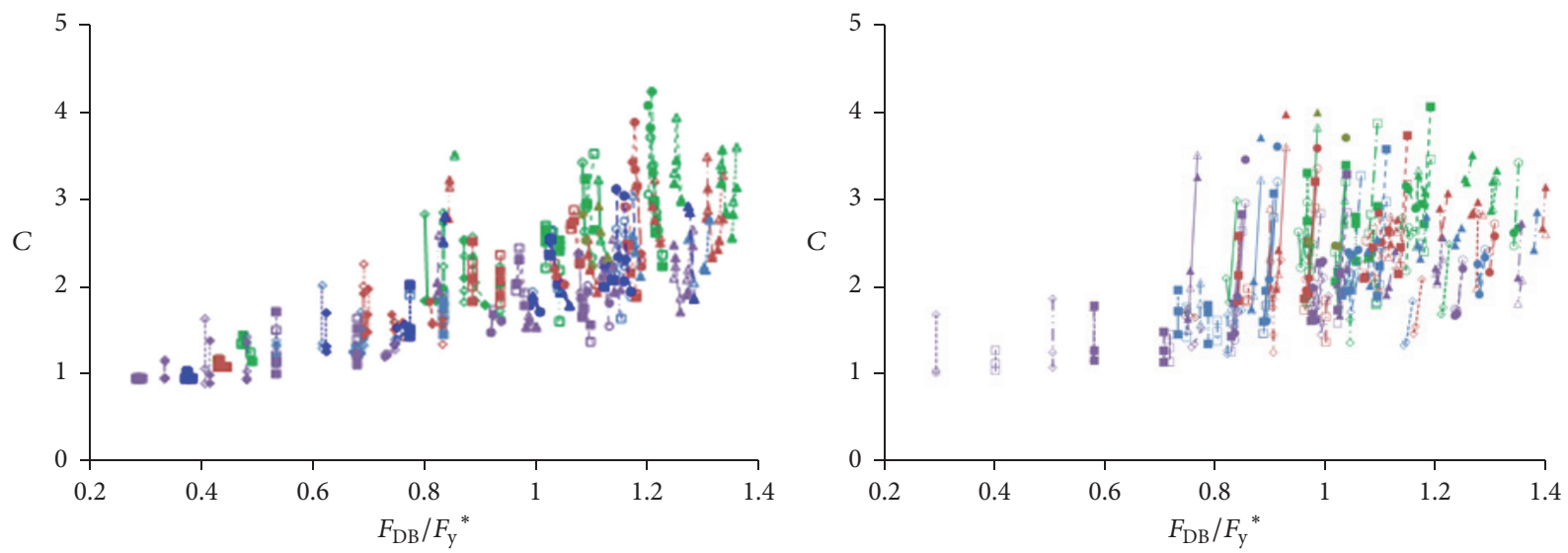

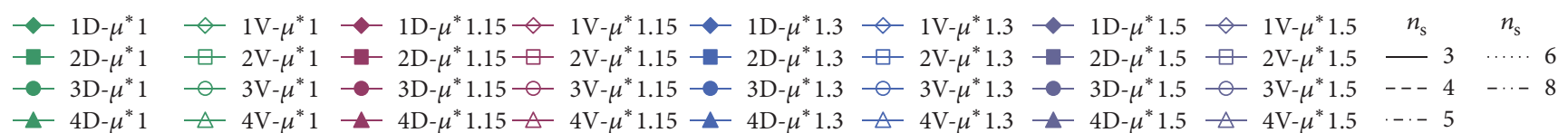
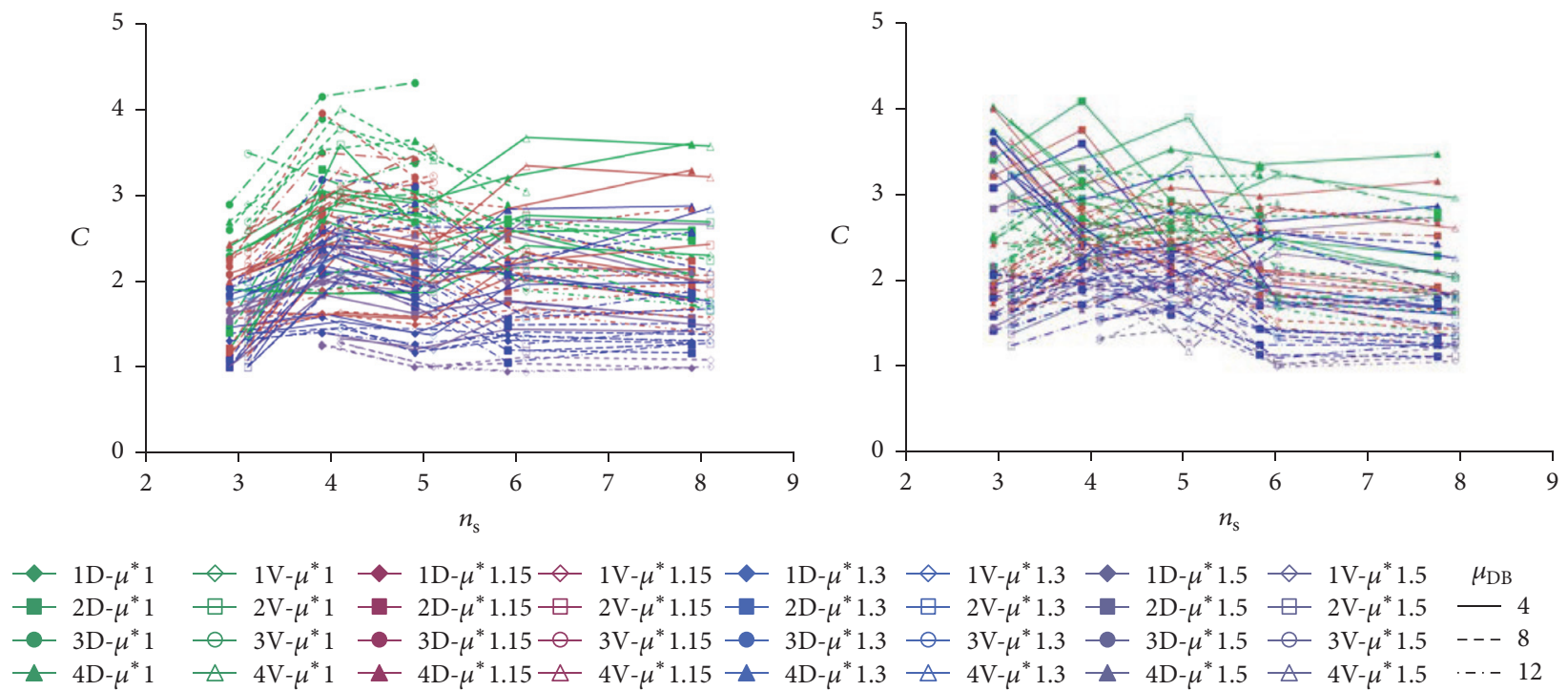

Figure 12: Continued. 

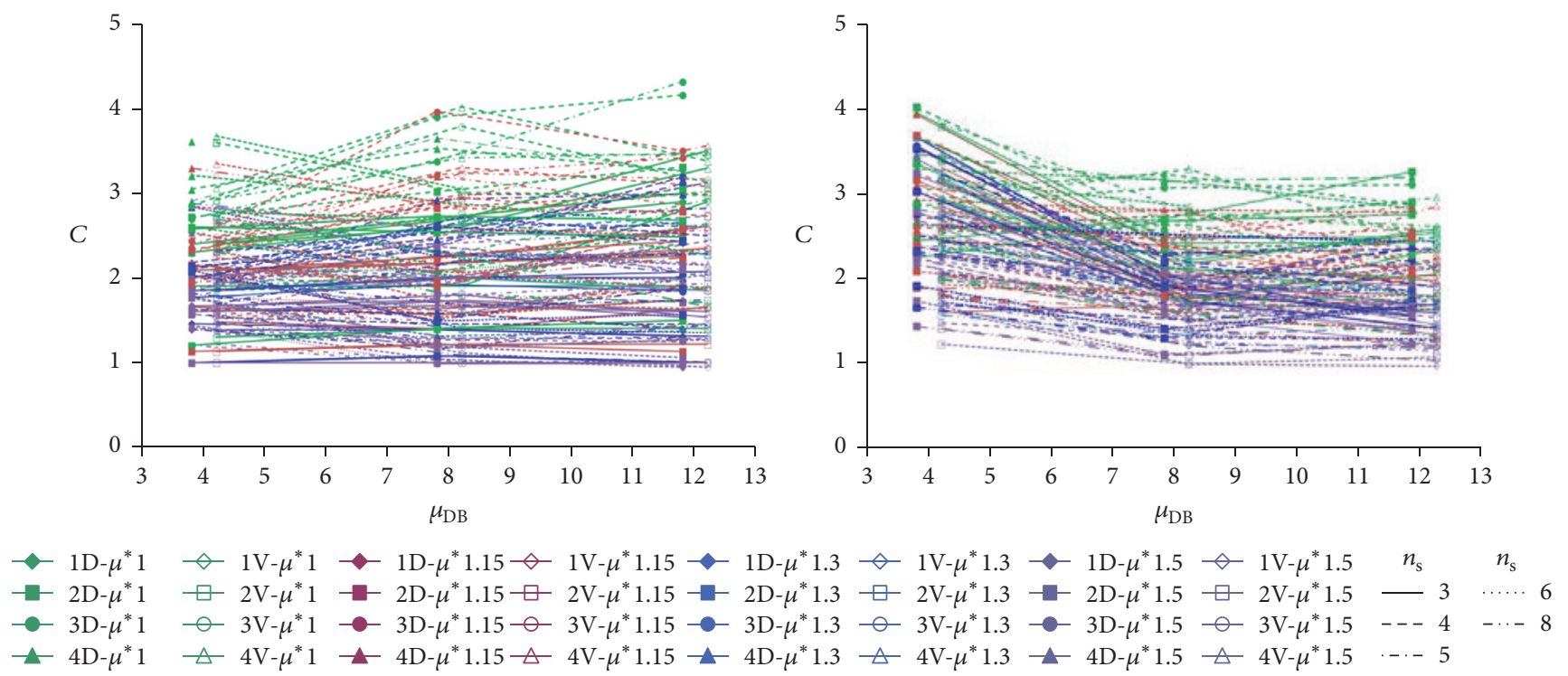

FIGURE 12: Correlation between $C$ and the ductility demand on the bracing $\mu_{\mathrm{DB}}$, the number of storeys $n_{\mathrm{s}}$, the ratio between periods $T_{\mathrm{B}}{ }^{*} / T^{*}$, and the ratio between resistances $F_{\mathrm{DB}} / F_{\mathrm{y}}{ }^{*}$.

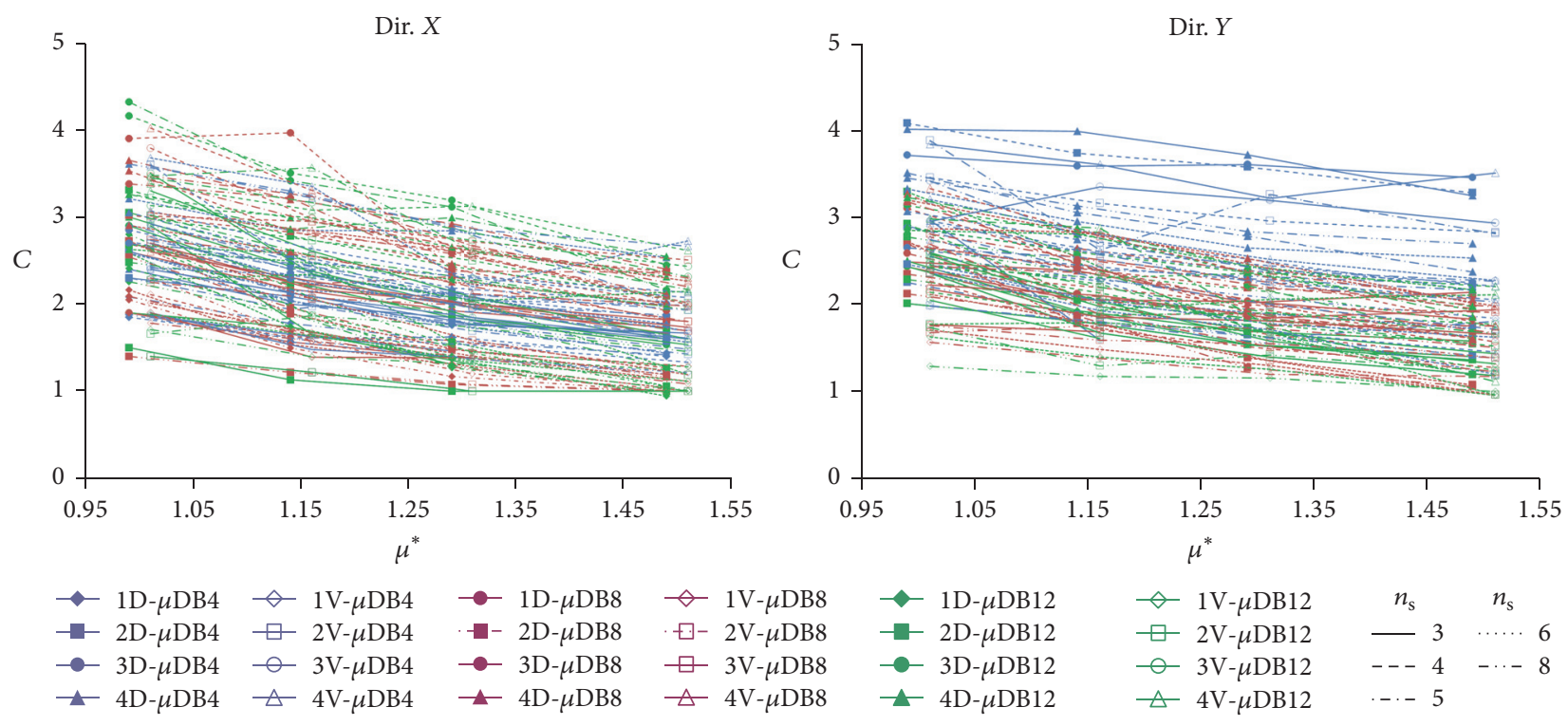

FIGURE 13: Correlation between $C$ and design structural ductility $\mu^{*}$.

performed considering the five above-mentioned structural parameters (see (16)). The values of the linear regression coefficients, which obtain the best fitting correlation $r^{2}$ between $C$, have been evaluated by applying the design procedure and the correction factor $C_{\mathrm{cal}}$ has been calculated through linear regression analysis (reported in Table 6 as regression (a)). The linear regression analysis carried out on the results of all case studies produced the diagrams showed in Figure 14 .

$$
\begin{aligned}
C_{\mathrm{cal}}= & m_{1} \cdot \mu^{*}+m_{2} \cdot \frac{T_{\mathrm{B}}{ }^{*}}{T^{*}}+m_{3} \cdot \frac{F_{\mathrm{DB}}}{F_{\mathrm{y}}{ }^{*}}+m_{4} \cdot n_{\mathrm{s}}+m_{5} \\
& \cdot \mu_{\mathrm{DB}},
\end{aligned}
$$

where $m_{1}, \ldots, m_{5}$ are the linear regression coefficients of the considered parameters.

As indicated by Table 6 and Figure 14(a), the coefficients $m_{4}$ and $m_{5}$ are negligible in determining the correction factor $C$. The lateral bar of each diagram shows the weight of the single parameters. A similar fitting correlation $r^{2}$ can be found by considering only the three main parameters associated with $m_{1}, m_{2}$, and $m_{3}$, named regression (b) (see Table 6 and Figure 14).

\section{Conclusions}

Fast sizing and verifications of the performance of EBDs could simplify the adoption of this particular strategy for 

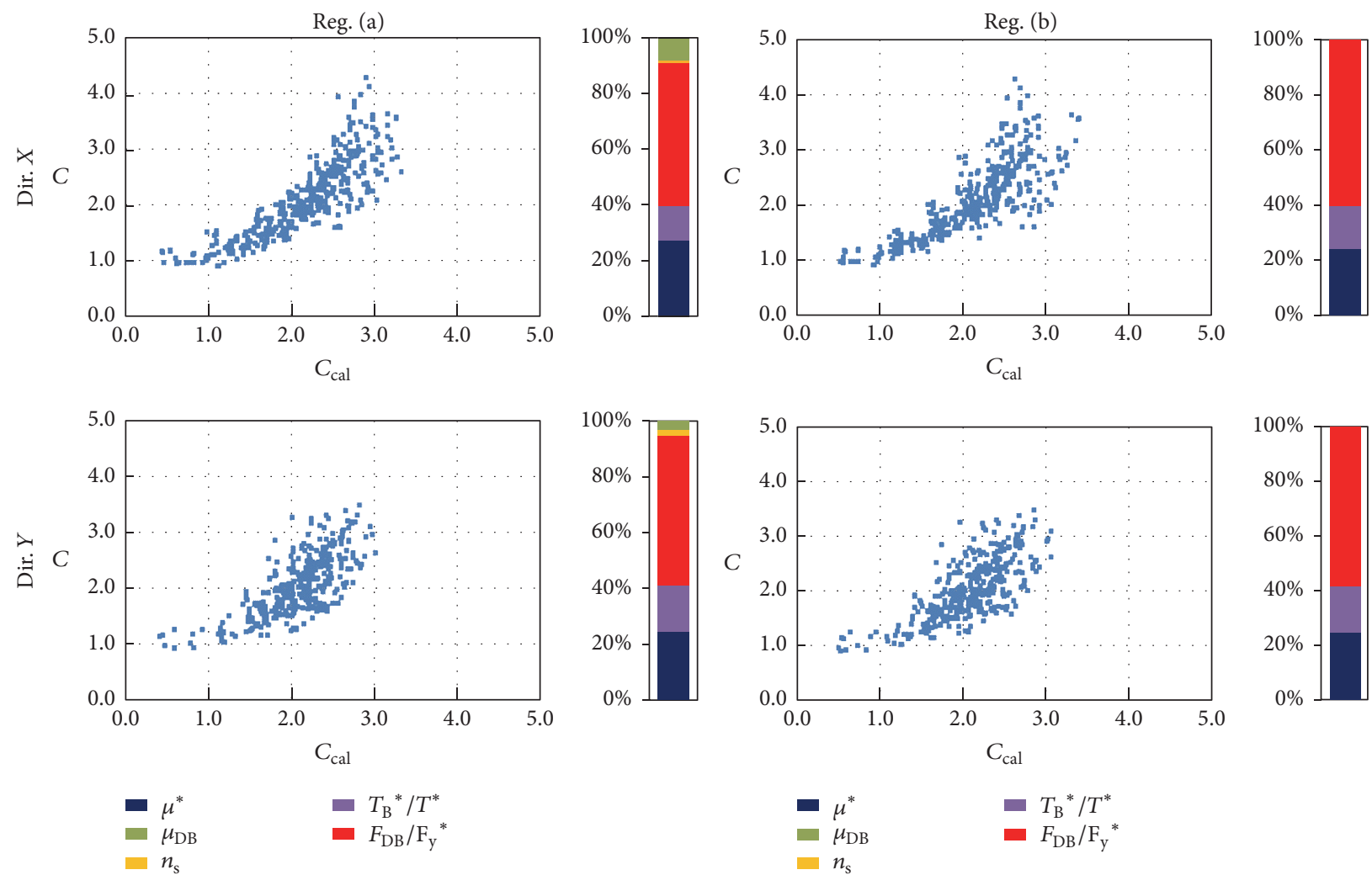

(a)
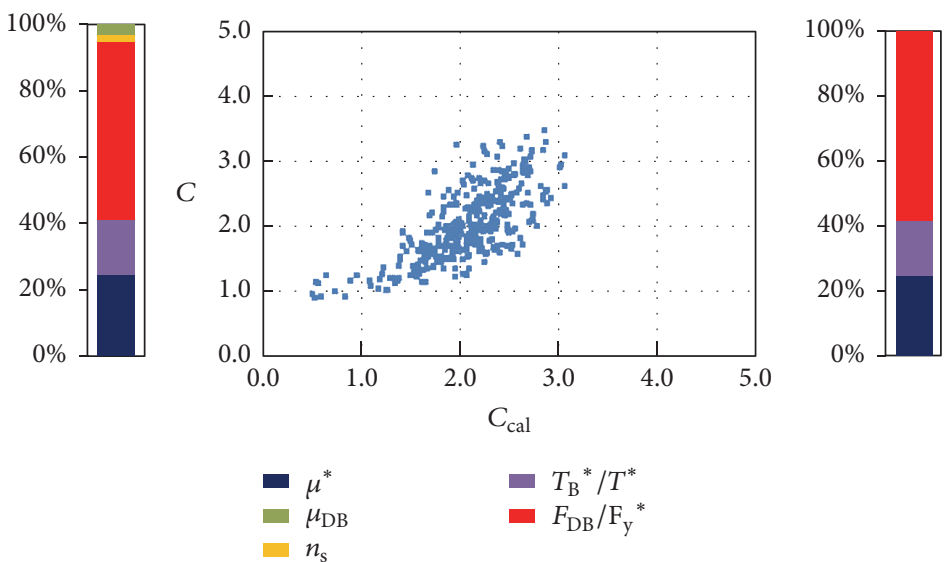

FIGURE 14: Regression analysis between the correction factors $C$ and $C_{\text {cal }}$ with the weight of the design parameters.

TABLE 6: Linear regression coefficients.

\begin{tabular}{cccccccc}
\hline Dir. & Regression & $m_{1}$ & $m_{2}$ & $m_{3}$ & $m_{4}$ & $m_{5}$ \\
\hline$X$ & (a) & -0.98 & 1.28 & 2.43 & 0.01 & 0.05 & - \\
& (b) & -0.78 & 1.40 & 2.54 & - & 0.97 \\
$Y$ & (a) & -0.87 & 1.57 & 2.33 & 0.02 & 0.97 \\
& (b) & -0.79 & 1.45 & 2.32 & - & 0.97 \\
\hline
\end{tabular}

structural retrofitting of existing buildings. Contemporarily the use of more simple linear analysis could allow for an increasing of the applications to real existing buildings. The design procedure proposed in this paper to evaluate the mechanical characteristics of the hysteretic EDBs showed their effectiveness in achieving the performance objective. The application of the procedure to a simple benchmark structure also confirmed a good agreement between numerical response obtained by NLSA and NLDA.

The outcomes of statistical analyses performed on about 1000 case studies have highlighted the efficiency of the design procedure in providing at least one solution satisfying the verification in most of cases studied. Only few of considered cases require specific local reinforcement to the structure elements despite the fact that the bracing is applied.

A correction factor $C$ representing the increasing of the behaviour factor of the braced building compared to that of the bare structure has been estimated. The analyses performed on all cases studies have shown that the correction factor $C$ varies from 1 to 4 , depending on the combinations of the three main design parameters: the target ductility $\mu^{*}$ of the bare structure; the ratio between the equivalent period of the braced structure and the period of the bare structure $T_{\mathrm{B}}{ }^{*} / T^{*}$; the ratio between the yield force of the equivalent dissipative bracing system and the yield force of the equivalent bare structure $F_{\mathrm{DB}} / F_{\mathrm{y}}{ }^{*}$.

Finally, it can be observed that in order to avoid the overloading of the structural elements (beams, columns, and joints) it is recommended that the target ductility of the bare structure should be $1<\mu^{*}<1.5$; the strength of the bracing system should not be too high with respect to the yield force of the bare structure $F_{\mathrm{BD}} / F_{\mathrm{y}}{ }^{*}<1.3$; the stiffness of the braced structure should not be too high with respect to the stiffness of the original structure $T_{\mathrm{B}}{ }^{*} / T^{*}>0.3$. 


\section{Symbols and Abbreviations}

$\begin{array}{ll}\text { Seismic Analysis } \\ \text { MDOF: } & \text { Multi-degree-of-freedom } \\ \text { SDOF: } & \text { Single-degree-of-freedom } \\ \text { S: } & \text { Elastoplastic SDOF of bare structure } \\ \text { DB: } & \text { Elastoplastic SDOF of dissipative bracing } \\ \text { S + DB: } & \text { Trilinear curve of the braced structure } \\ \text { E(S + DB): } & \text { Equivalent elastic system of S + DB } \\ \text { EP(S + DB): } & \text { Equivalent elastoplastic system of S + DB } \\ \text { LSA: } & \text { Linear static analysis } \\ \text { NLDA: } & \text { Nonlinear dynamic analysis } \\ \text { NLSA: } & \text { Nonlinear static analysis } \\ \text { FDE: } & \text { Frequent Design Earthquake } \\ \text { SDE: } & \text { Serviceability Design Earthquake } \\ \text { BDE: } & \text { Basic Design Earthquake } \\ \text { MCE: } & \text { Maximum Considered Earthquake } \\ T_{C}: & \text { Upper limit of the period of the constant } \\ & \text { spectral acceleration branch } \\ \xi: & \text { Viscous damping ratio } \\ \text { T1: } & \text { Topographic factor } \\ \text { PGA: } & \text { Peak ground acceleration. }\end{array}$

Bare Structure (S)

$n_{\mathrm{s}}: \quad$ Number of storeys

$T_{1}$ : Fundamental period of vibration of a building

$m_{i}$ : Mass of storey $i$

$h_{i}$ : Interstorey height of storey $i$

$s_{i}$ : Displacement of storey $i$ from LSA

$\Delta s_{i}:$ Interstorey displacement from LSA

$s_{\mathrm{TOT}}$ : Maximum top displacement form LSA

$F_{i}$ : $\quad$ Horizontal seismic force at storey $i$

$\Gamma: \quad$ Transformation factor of $S$

$m^{*}$ : Equivalent mass of $\mathrm{S}$

$T^{*}$ : Equivalent period of $\mathrm{S}$

$F_{\mathrm{y}}{ }^{*}$ : Yield force of $\mathrm{S}$

$d_{\mathrm{y}}{ }^{*}$ : Yield displacement of $\mathrm{S}$

$k_{F}^{*}$ : Elastic stiffness of S

$d_{\mathrm{u}}{ }^{*}$ : Ultimate displacement of S

$\mu_{F}^{*}$ : Maximum ductility of $\mathrm{S}$

$\mu^{*}: \quad$ Target ductility of S

$F_{\mathrm{y}, i}:$ Yield force of storey $i$ of $\mathrm{S}$

$d_{\mathrm{y}, i}:$ Yield displacement of storey $i$ of $\mathrm{S}$

$k_{F, i}:$ Elastic stiffness of storey $i$ of $S$

$u_{i}$ : Normalized modal displacement of storey $i$ of $S$

$q$ : Behaviour factor of the bare structure

$q_{0}$ : Basic value of the behaviour factor $q$

Dissipative Bracing (DB) System

EDB: Energy Dissipation Bracing

$F_{\mathrm{DB}}$ : Yield force of $\mathrm{DB}$

$d_{\mathrm{DBy}}$ : Yield displacement of DB

$k_{\mathrm{DB}}$ : Elastic stiffness of DB

$d_{\mathrm{DBu}}$ : Ultimate displacement of $\mathrm{DB}$

$\mu_{\mathrm{DB}}$ : Design ductility of $\mathrm{DB}$

$k_{\mathrm{DB}, i}$ : Elastic stiffness of storey $i$ of DB

$F_{\mathrm{DB}, i}$ : Yield force of storey $i$ of DB.
Braced Structure $(E P(S+D B))$

$\Gamma_{\mathrm{B}}: \quad$ Transformation factor of $\mathrm{EP}(\mathrm{S}+\mathrm{DB})$

$m_{\mathrm{B}}{ }^{*}: \quad$ Equivalent mass of $\mathrm{EP}(\mathrm{S}+\mathrm{DB})$

$T_{\mathrm{B}}{ }^{*}: \quad$ Equivalent period of $\mathrm{EP}(\mathrm{S}+\mathrm{DB})$

$k_{\mathrm{B}}^{*}: \quad$ Elastic stiffness of $\mathrm{EP}(\mathrm{S}+\mathrm{DB})$

$k_{\mathrm{tot}, i}: \quad$ Total stiffness of storey $i$ of $\mathrm{S}+\mathrm{DB}$

$F_{\mathrm{By}}{ }^{*}$ : $\quad$ Yield force of the $\mathrm{EP}(\mathrm{S}+\mathrm{DB})$

$d_{\mathrm{By}}{ }^{*}$ : $\quad$ Yield displacement of the braced structure

$d_{\mathrm{Bu}}{ }^{*}: \quad$ Ultimate displacement of the braced structure

$\mu_{\mathrm{B}}{ }^{*}: \quad$ Ductile capacity of the braced structure

$d_{\mathrm{Be}}{ }^{*}: \quad$ Elastic displacement of $\mathrm{E}(\mathrm{S}+\mathrm{DB})$ at $\mathrm{BDE}$

$d_{\mathrm{Bm}}{ }^{*}: \quad$ Maximum displacement of $\mathrm{EP}(\mathrm{S}+\mathrm{DB})$ at $\mathrm{BDE}$

$d_{\mathrm{Bt}}{ }^{*}: \quad$ Target displacement of $\mathrm{EP}(\mathrm{S}+\mathrm{DB})$

$V_{\mathrm{Ed}, i}: \quad$ Design shear force of storey $i$ required by LSA

$m_{k}, M_{k}$ : Stiffness correction factors

$m_{F}, M_{F}$ : Strength correction factors

$q_{\mathrm{B}}$ : $\quad$ Behaviour factor of the braced structure

C: $\quad$ Correction coefficient of the behaviour factor $q$.

Dissipative Braces

HD: Hysteretic Damper

$\mathrm{R}: \quad$ Rigid bracing truss

$k_{\mathrm{DB}, i, s}:$ Stiffness of the single BD of storey $i$

$F_{\mathrm{DB}, i, s,}$ : Yield strength of the single DB of storey $i$

$n_{\mathrm{DB}, i}$ : Number of DBs of storey $i$

$\phi_{s}: \quad$ Angle between the brace and the horizontal

$k_{\mathrm{HD}, i, s}$ : Elastic stiffness of single HD of storey $i$

$F_{\mathrm{HD}, i, s}$ : Yield force of single HD of storey $i$

$\mu_{\mathrm{HD}}$ : Design ductility of single HD of storey $i$

$k_{\mathrm{R}, i, s}$ : Elastic stiffness of the single R of storey $i$.

\section{Conflicts of Interest}

The authors declare that there are no conflicts of interest regarding the publication of this paper.

\section{Acknowledgments}

This study was funded by the Italian Department of Civil Protection within the RELUIS 2010-2013, RELUIS 2014 projects, and MIUR within the PRIN 2012 project. The authors would like to acknowledge STS Software for supplying finite element program. The work performed by Gianluca Auletta, Ph.D., for the numerical modelling is also acknowledged.

\section{References}

[1] A. Di Cesare, F. C. Ponzo, M. Vona et al., "Identification of the structural model and analysis of the global seismic behaviour of a RC damaged building," Soil Dynamics and Earthquake Engineering, vol. 65, pp. 131-141, 2014.

[2] V. Ciampi, "Development of passive energy dissipation techniques for buildings," in Proceedings of the Post-SMIRT Conference Seminar on Seismic Isolation, Energy Dissipation and Control of Vibrations of Structures, pp. 495-510, Capri, Italy, 1993. 
[3] Keh-Chyuan Tsai, Huan-Wei Chen, Ching-Ping Hong, and Yung-Feng $\mathrm{Su}$, "Design of steel triangular plate energy absorbers for seismic-resistant construction," Earthquake Spectra, vol. 9, no. 3, pp. 505-528, 1993.

[4] T. T. Soong and G. F. Dargush, Passive Energy Dissipation Systems in Structural Engineering, Wiley, Chichester, UK, 1997.

[5] M. C. Constantinou, T. T. Soong, and G. F. Dargush, "Passive energy dissipation systems for structural design and retrofit," in Monograph Series no.1, MCEER, State University of New York, New York, NY, USA, 2001.

[6] C. Christopoulos and A. Filiatrault, Principles of Passive Supplemental Damping and Seismic Isolation, IUSS Press, Istituto Universitario di Studi Superiori di Pavia, Pavia, Italy, 2007.

[7] M. Dolce, D. Cardone, E. Coelho, and F. C. Ponzo, "Experimental behaviour of R/C frames retrofitted with dissipating and REcentring braces," Journal of Earthquake Engineering, vol. 8, no. 3, pp. 361-396, 2004.

[8] M. Dolce, D. Cardone, F. C. Ponzo, and C. Valente, "Shaking table tests on reinforced concrete frames without and with passive control systems," Earthquake Engineering and Structural Dynamics, vol. 34, no. 14, pp. 1687-1717, 2005.

[9] A. Di Cesare, F. C. Ponzo, and G. Auletta, "Q-factors of reinforced concrete structures retrofitted with hysteretic energy dissipating bracing system," in Proceedings of the 15th World Conference on Earthquake Engineering, Lisboa, Portugal, 2012.

[10] F. C. Ponzo, A. Di Cesare, and D. Nigro, "Visco-re-centring energy dissipating system for seismic protection of framed buildings," International Journal of Mechanics, vol. 7, no. 4, pp. 370-378, 2013.

[11] M. Bayat and M. Bayat, "Seismic behavior of special momentresisting frames with energy dissipating devices under near source ground motions," Steel and Composite Structures, vol. 16, no. 5, pp. 533-557, 2014.

[12] Y. Y. Lin, M. H. Tsai, J. S. Hwang, and K. C. Chang, "Direct displacement-based design for building with passive energy dissipation systems," Engineering Structures, vol. 25, no. 1, pp. 25-37, 2003.

[13] Y.-Y. Lin, K.-C. Chang, and C.-Y. Chen, "Direct displacementbased design for seismic retrofit of existing buildings using nonlinear viscous dampers," Bulletin of Earthquake Engineering, vol. 6, no. 3, pp. 535-552, 2008.

[14] A. V. Bergami and C. Nuti, "A design procedure of dissipative braces for seismic upgrading structures," Earthquake and Structures, vol. 4, no. 1, pp. 85-108, 2013.

[15] F. Mazza and A. Vulcano, "Equivalent viscous damping for displacement-based seismic design of hysteretic damped braces for retrofitting framed buildings," Bulletin of Earthquake Engineering, vol. 12, no. 6, pp. 2797-2819, 2014.

[16] Applied Technology Council, Seismic Evaluation and Retrofit of Concrete Buildings, ATC-40, Applied Technology Council, Redwood City, Calif, USA, 1996.

[17] FEMA-273, NEHRP Guidelines for the Seismic Rehabilitation of Buildings, Building Seismic Safety Council (BSSC), Washington, DC, USA; Applied Technology Council (ATC), Redwood City, Calif, USA, 1997.

[18] FEMA-274, NEHRP Commentary on the Guidelines for the Seismic Rehabilitation of Buildings, Building Seismic Safety Council (BSSC), Washington, DC, USA; Applied Technology Council (ATC), Redwood City, Calif, USA, 1997.

[19] FEMA-450, NEHRP Recommended Provisions for Seismic Regulations for New buildings and Other Structures, Building Seismic
Safety Council National Institute of Building Sciences, Washington, DC, USA, 2003.

[20] Circ. n. 617, "Application of Italian Technical Code for Constructions NTC 2008," 2009.

[21] A. Benavent-Climent and D. Escolano-Margarit, "Shaking table tests of structures with hysteretic dampers: experimental results versus prediction using non-linear static methods," Bulletin of Earthquake Engineering, vol. 10, no. 6, pp. 1857-1883, 2012.

[22] M. Palermo, S. Silvestri, T. Trombetti, and L. Landi, "Force reduction factor for building structures equipped with added viscous dampers," Bulletin of Earthquake Engineering, vol. 11, no. 5, pp. 1661-1681, 2013.

[23] F. Mazza, M. Mazza, and A. Vulcano, "Displacement-based seismic design of hysteretic damped braces for retrofitting inelevation irregular r.c. framed structures," Soil Dynamics and Earthquake Engineering, vol. 69, pp. 115-124, 2015.

[24] EN 1998-1, Eurocode 8: Design of Structures for Earthquake Resistance-Part 1: General Rules, Seismic Actions and Rules for Buildings, European Committee for Standardization (CEN), Brussel,Belgium, 2005.

[25] NTC, Italian Technical Code for Constructions, Decreto Ministeriale 14 Gennaio 2008, Rome, Italy, 2008.

[26] FEMA-356, Pre-Standard and Commentary for the Seismic Rehabilitation of Buildings, American Society of Civil Engineers, Reston, Va, USA, 2000.

[27] A. Di Cesare, F. C. Ponzo, D. Nigro, M. Dolce, and C. Moroni, "Experimental and numerical behaviour of hysteretic and visco-recentring energy dissipating bracing systems," Bulletin of Earthquake Engineering, vol. 10, no. 5, pp. 1585-1607, 2012.

[28] A. Di Cesare, F. C. Ponzo, and D. Nigro, "Assessment of the performance of hysteretic energy dissipation bracing systems," Bulletin of Earthquake Engineering, vol. 12, no. 6, pp. 2777-2796, 2014.

[29] F. C. Ponzo, A. Di Cesare, D. Nigro et al., "Jet-pacs project: dynamic experimental tests and numerical results obtained for a steel frame equipped with hysteretic damped chevron braces," Journal of Earthquake Engineering, vol. 16, no. 5, pp. 662-685, 2012.

[30] S. Sorace, G. Terenzi, and F. Fadi, "Shaking table and numerical seismic performance evaluation of a fluid viscous-dissipative bracing system," Earthquake Spectra, vol. 28, no. 4, pp. 16191642, 2012.

[31] F. Mazza, "Nonlinear seismic analysis of unsymmetric-plan structures retrofitted by hysteretic damped braces," Bulletin of Earthquake Engineering, vol. 14, no. 4, pp. 1311-1331, 2016.

[32] M. Palermo, S. Silvestri, G. Gasparini, and T. Trombetti, "Crescent shaped braces for the seismic design of building structures," Materials and Structures, vol. 48, no. 5, pp. 1485-1502, 2015.

[33] S. Sorace and G. Terenzi, "Dissipative bracing-based seismic retrofit of R/C school buildings," Open Construction and Building Technology Journal, vol. 6, pp. 334-345, 2012.

[34] S. Sorace, G. Terenzi, and C. Mori, "Passive energy dissipationbased retrofit strategies for R/C frame water towers," Engineering Structures, vol. 106, pp. 385-398, 2016.

[35] M. Dolce and R. Marnetto, "Energy dissipating coverplates for steel brace joints," in Proceedings of the 5th World Conference on Joints, Bearings and Seismic Systems for Concrete Structures, Rome, Italy, October 2001.

[36] CDS-Win, "Italian technical-scientific software with OpenSees inside for calculation of reinforced concrete building," 2014. 
[37] N. M. Newmark and W. J. Hall, Earthquake Spectra and Design, EERI Monograph Series, EERI, Berkley, Calif, USA, 1982.

[38] P. Fajfar and H. Krawinkler, Nonlinear Seismic Analysis and Design of Reinforced Concrete Buildings, Elsevier, London, UK, 1992.

[39] E. Miranda and V. V. Bertero, "Evaluation of strength reduction factors for earthquake-resistant design," Earthquake Spectra, vol. 10, no. 2, pp. 357-379, 1994.

[40] T. Paulay and M. J. N. Priestley, Seismic Design of Reinforced Concrete and Masonry Buildings, John Wiley \& Sons, New York, NY, USA, 1992.

[41] I. Takewaki, S. Yoshitomi, K. Uetani, and M. Tsuji, "Nonmonotonic optimal damper placement via steepest direction search," Earthquake Engineering and Structural Dynamics, vol. 28, no. 6, pp. 655-670, 1999.

[42] O. Lavan and R. Levy, "Optimal peripheral drift control of 3D irregular framed structures using supplemental viscous dampers," Journal of Earthquake Engineering, vol. 10, no. 6, pp. 903-923, 2006.

[43] F. C. Ponzo, A. Di Cesare, G. Arleo, and P. Totaro, "Protezione sismica di edifici esistenti con controventi dissipativi di tipo isteretico: aspetti progettuali ed esecutivi.," Progettazione Sismica, vol. 1, pp. 37-60, 2010. 


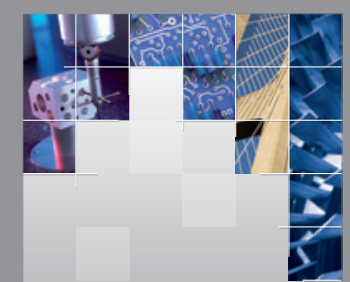

\section{Enfincering}
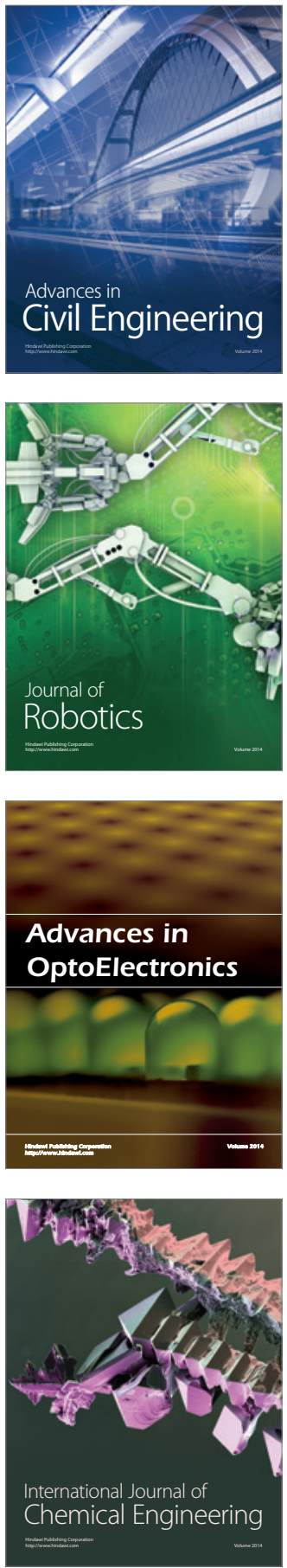

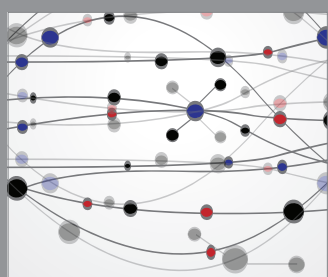

The Scientific World Journal

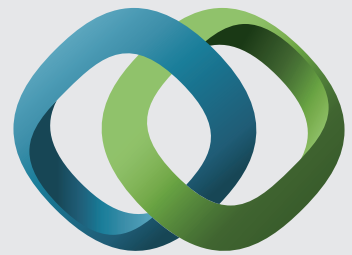

\section{Hindawi}

Submit your manuscripts at

https://www.hindawi.com
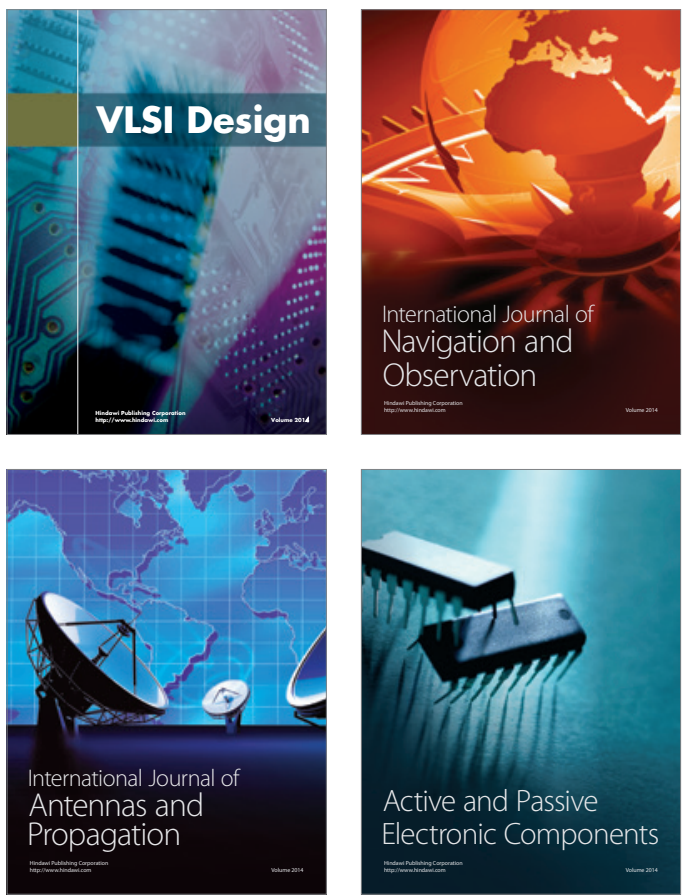
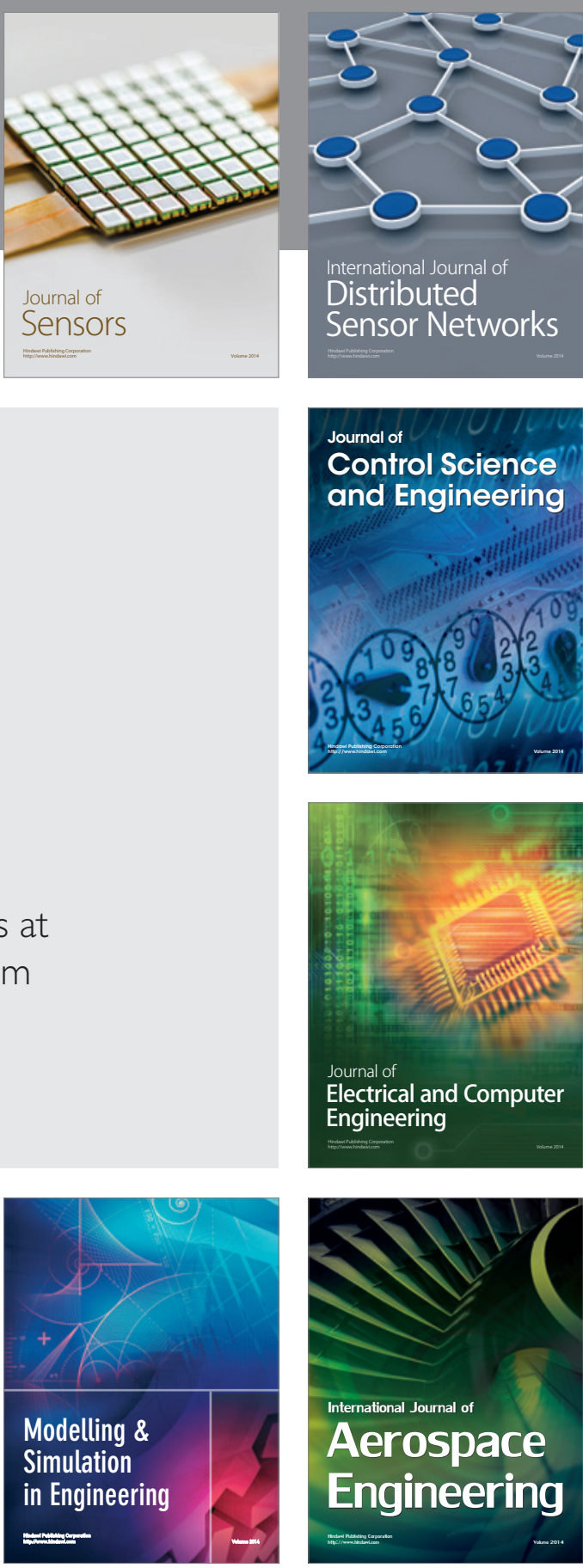

International Journal of

Distributed

Sensor Networks

$-$

Joumal of

Control Science

and Engineering
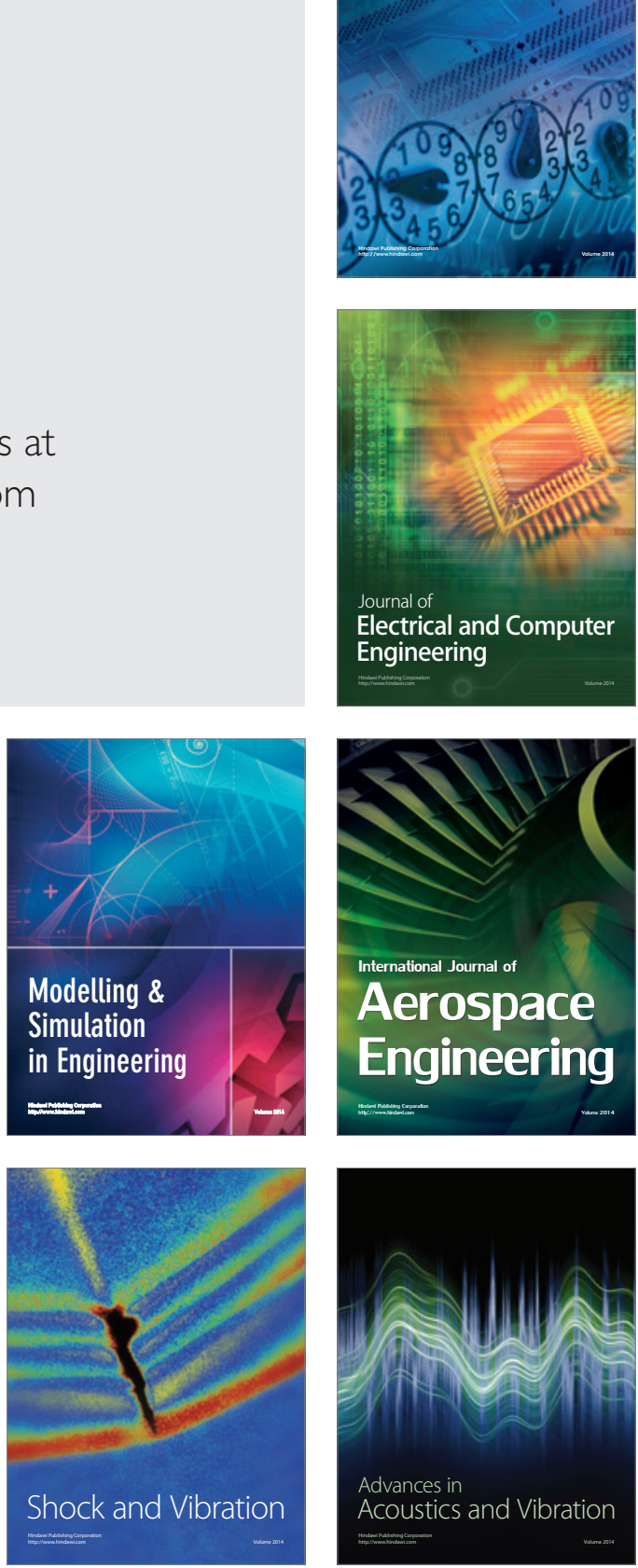